\title{
Global Strategy for the Diagnosis, Management, and Prevention of Chronic Obstructive Pulmonary Disease GOLD Executive Summary
}

\author{
Klaus F. Rabe ${ }^{1}$, Suzanne Hurd², Antonio Anzueto ${ }^{3}$, Peter J. Barnes ${ }^{4}$, Sonia A. Buist ${ }^{5}$, Peter Calverley ${ }^{6}$, \\ Yoshinosuke Fukuchi ${ }^{7}$, Christine Jenkins ${ }^{8}$, Roberto Rodriguez-Roisin ${ }^{9}$, Chris van Weel ${ }^{10}$, and Jan Zielinski ${ }^{11}$ \\ ${ }^{1}$ Leiden University Medical Center, Pulmonology, Leiden, The Netherlands; ${ }^{2}$ Global Initiative for Chronic Obstructive Lung Disease, \\ Gaithersburg, Maryland; ${ }^{3}$ University of Texas Health Science Center, San Antonio, Texas; ${ }^{4}$ National Heart and Lung Institute, London, \\ United Kingdom; ${ }^{5}$ Oregon Health and Science University, Portland, Oregon; ${ }^{6}$ University Hospital Aintree, Liverpool, United Kingdom; \\ ${ }^{7}$ Asian Pacific Society of Respirology, Tokyo, Japan; ${ }^{8}$ Woolcock Institute of Medical Research, North Sydney, Australia; \\ ${ }^{9}$ Hospital Clinic, Barcelona, Spain; ${ }^{10}$ University of Nijmegen, Nijmegen, The Netherlands; and ${ }^{11}$ Institute of TB and Lung Diseases, \\ Warsaw, Poland
}

Chronic obstructive pulmonary disease (COPD) remains a major public health problem. It is the fourth leading cause of chronic morbidity and mortality in the United States, and is projected to rank fifth in $\mathbf{2 0 2 0}$ in burden of disease worldwide, according to a study published by the World Bank/World Health Organization. Yet, COPD remains relatively unknown or ignored by the public as well as public health and government officials. In 1998, in an effort to bring more attention to COPD, its management, and its prevention, a committed group of scientists encouraged the U.S. National Heart, Lung, and Blood Institute and the World Health Organization to form the Global Initiative for Chronic Obstructive Lung Disease (GOLD). Among the important objectives of GOLD are to increase awareness of COPD and to help the millions of people who suffer from this disease and die prematurely of it or its complications. The first step in the GOLD program was to prepare a consensus report, Global Strategy for the Diagnosis, Management, and Prevention of COPD, published in 2001. The present, newly revised document follows the same format as the original consensus report, but has been updated to reflect the many publications on COPD that have appeared. GOLD national leaders, a network of international experts, have initiated investigations of the causes and prevalence of COPD in their countries, and developed innovative approaches for the dissemination and implementation of COPD management guidelines. We appreciate the enormous amount of work the GOLD national leaders have done on behalf of their patients with COPD. Despite the achievements in the 5 years since the GOLD report was originally published, considerable additional work is ahead of us if we are to control this major public health problem. The GOLD initiative will continue to bring COPD to the attention of governments, public health officials, health care workers, and the general public, but a concerted effort by all involved in health care will be necessary.

Keywords: COPD; guidelines; human; chronic disease

(Received in original form March 20, 2007; accepted in final form May 15, 2007) Correspondence and requests for reprints should be addressed to Prof. Klaus F. Rabe, M.D., Ph.D., Leiden University Medical Center, Pulmonology, P.O. Box 9600, NL-2300 RC, Leiden, The Netherlands. E-mail: k.f.rabe@lumc.nl.

This article has an online supplement, which is accessible from this issue's table of contents at www.atsjournals.org

This document is available in a different format on the Global Initiative for Chronic Obstructive Lung Disease (GOLD) website at www.goldcopd.org/download.asp? intld $=380$

Am J Respir Crit Care Med Vol 176. pp 532-555, 2007

Originally Published in Press as DOI: 10.1164/rccm.200703-456SO on May 16, 2007

Internet address: www.atsjournals.org

\section{CONTENTS}

Introduction

Methodology and Summary of New Recommendations

Levels of Evidence

1. Definition, Classification of Severity, and Mechanisms of COPD

Definition

Spirometric Classification of Severity and Stages of COPD

Pathology, Pathogenesis, and Pathophysiology

2. Burden of COPD

Epidemiology

Prevalence

Morbidity

Mortality

Economic and Social Burden of COPD

Risk Factors

Genes

Inhalational Exposures

Sex

Infection

Socioeconomic Status

3. The Four Components of COPD Management

Introduction

Component 1: Assess and Monitor Disease Initial Diagnosis

Ongoing Monitoring and Assessment

Component 2: Reduce Risk Factors

Smoking Prevention and Cessation

Occupational Exposures

Indoor and Outdoor Air Pollution

Component 3: Manage Stable COPD

Introduction

Education

Pharmacologic Treatments

Nonpharmacologic Treatments

Special Considerations

Component 4: Manage Exacerbations

Introduction

Diagnosis and Assessment of Severity

Home Management

Hospital Management

Hospital Discharge and Follow-up

4. Translating Guideline Recommendations to the Context of

(Primary) Care

Diagnosis

Respiratory Symptoms 
Spirometry

Comorbidities

Reducing Exposure to Risk Factors

Implementation of COPD Guidelines

\section{INTRODUCTION}

Chronic obstructive pulmonary disease (COPD) is a major cause of chronic morbidity and mortality throughout the world. Many people suffer from this disease for years and die prematurely of it or its complications. The goals of the Global Initiative for Chronic Obstructive Lung Disease (GOLD) are to improve prevention and management of COPD through a concerted worldwide effort of people involved in all facets of health care and health care policy, and to encourage an expanded level of research interest in this highly prevalent disease.

One strategy to help achieve the objectives of GOLD is to provide health care workers, health care authorities, and the general public with state-of-the-art information about COPD and specific recommendations on the most appropriate management and prevention strategies. The GOLD report, Global Strategy for the Diagnosis, Management, and Prevention of $C O P D$, is based on the best-validated current concepts of COPD pathogenesis and the available evidence on the most appropriate management and prevention strategies. A major part of the GOLD report is devoted to the clinical management of COPD and presents a management plan with four components: (1) assess and monitor disease, (2) reduce risk factors, (3) manage stable COPD, and (4) manage exacerbations. A new section at the end of the document will assist readers in translating guideline recommendations to the context of (primary) care.

GOLD is a partner organization in a program launched in March 2006 by the World Health Organization's Global Alliance Against Chronic Respiratory Diseases (GARD). Through the work of the GOLD committees, and in cooperation with GARD initiatives, progress toward better care for all patients with COPD should be substantial in the next decade.

\section{Methodology and Summary of New Recommendations}

After the release of the 2001 GOLD report, a science committee was formed and charged with keeping the GOLD documents up-to-date by reviewing published research, evaluating the impact of this research on the management recommendations in the GOLD documents, and posting yearly updates of these documents on the GOLD website (www.goldcopd.org). The methodology is described in each update (see, e.g., the 2005 update in Reference 3 and the APPENDIX in the online supplement).

In January 2005, the GOLD science committee initiated preparation of this revised 2006 document on the basis of the most current scientific literature. Multiple meetings were held, including several with GOLD national leaders to discuss concepts and new recommendations. Before its publications, several reviewers were invited to submit comments.

A summary of the issues presented in this report include the following:

1. Recognition that COPD is characterized by chronic airflow limitation and a range of pathologic changes in the lung, some significant extrapulmonary effects, and important comorbidities that may contribute to the severity of the disease in individual patients.

2. In the definition of COPD, the phrase "preventable and treatable" has been incorporated following the American Thoracic Society/European Respiratory Society recom- mendations to recognize the need to present a positive outlook for patients, to encourage the health care community to take a more active role in developing programs for COPD prevention, and to stimulate effective management programs to treat those with the disease.

3. The spirometric classification of severity of COPD now includes four stages: stage I, mild; stage II, moderate; stage III, severe; stage IV, very severe. A fifth category, "stage 0, at risk," that appeared in the 2001 report is no longer included as a stage of COPD, as there is incomplete evidence that the individuals who meet the definition of "at risk" (chronic cough and sputum production, normal spirometry) necessarily progress on to stage I. Nevertheless, the importance of the public health message that chronic cough and sputum are not normal is unchanged.

4. The spirometric classification of severity continues to recommend use of the fixed ratio post-bronchodilator $\mathrm{FEV}_{1} / \mathrm{FVC}<0.7$ to define airflow limitation. Using the fixed ratio $\left(\mathrm{FEV}_{1} / \mathrm{FVC}\right)$ is particularly problematic in patients with milder disease who are elderly because the normal process of aging affects lung volumes. Postbronchodilator reference values in this population are urgently needed to avoid potential overdiagnosis.

5. Section 2, BuRdEN OF COPD, provides references to published data from prevalence surveys to estimate that about 15 to $25 \%$ of adults aged 40 years and older may have airflow limitation classified as stage I mild COPD or higher and that the prevalence of COPD (stage I, mild COPD and higher) is appreciably higher in smokers and ex-smokers than in nonsmokers, in those over 40 years compared with those younger than 40 , and higher in men than in women. The section also provides new data on COPD morbidity and mortality.

6. Cigarette smoke is the most commonly encountered risk factor for COPD and elimination of this risk factor is an important step toward prevention and control of COPD. However, other risk factors for COPD should be taken into account where possible, including occupational dusts and chemicals, and indoor air pollution from biomass cooking and heating in poorly ventilated dwellings-the latter especially among women in developing countries.

7. The section on pathology, pathogenesis, and pathophysiology, continues with the theme that inhaled cigarette smoke and other noxious particles cause lung inflammation, a normal response which appears to be amplified in patients who develop COPD. The section has been considerably updated and revised.

8. Management of COPD continues to be presented in four components: (1) assess and monitor disease, (2) reduce risk factors, (3) manage stable COPD, and (4) manage exacerbations. All components have been updated on the basis of recently published literature. Throughout it is emphasized that the overall approach to managing stable COPD should be individualized to address symptoms and improve quality of life.

9. In Component 4, Manage Exacerbations, a COPD exacerbation is defined as "an event in the natural course of the disease characterized by a change in the patient's baseline dyspnea, cough, and/or sputum that is beyond normal day-to-day variations, is acute in onset, and may warrant a change in regular medication in a patient with underlying COPD." 
10. It is widely recognized that a wide spectrum of health care providers is required to ensure that COPD is diagnosed accurately, and that individuals who have COPD are treated effectively. The identification of effective health care teams will depend on the local health care system, and much work remains to identify how best to build these health care teams. A section on COPD implementation programs and issues for clinical practice has been included but it remains a field that requires considerable attention.

\section{Levels of Evidence}

Levels of evidence are assigned to management recommendations where appropriate in subsections of section 3 that discuss COPD management, with the system used in previous GOLD reports (Table 1). Evidence levels are enclosed in parentheses after the relevant statement-for example, (Evidence A).

\section{DEFINITION, CLASSIFICATION OF SEVERITY, AND MECHANISMS OF COPD}

\section{Definition}

Chronic obstructive pulmonary disease (COPD) is a preventable and treatable disease with some significant extrapulmonary effects that may contribute to the severity in individual patients. Its pulmonary component is characterized by airflow limitation that is not fully reversible. The airflow limitation is usually progressive and associated with an abnormal inflammatory response of the lung to noxious particles or gases.

The chronic airflow limitation characteristic of COPD is caused by a mixture of small airway disease (obstructive bronchiolitis) and parenchymal destruction (emphysema), the relative contributions of which vary from person to person. Airflow limitation is best measured by spirometry, because this is the most widely available, reproducible test of lung function.

Because COPD often develops in longtime smokers in middle age, patients often have a variety of other diseases related to either smoking or aging (4). COPD itself also has significant extrapulmonary (systemic) effects that lead to comorbid conditions (5). Thus, COPD should be managed with careful attention also paid to comorbidities and their effect on the patient's quality of life. A careful differential diagnosis and comprehensive assessment of severity of comorbid conditions should be performed in every patient with chronic airflow limitation.

\section{Spirometric Classification of Severity and Stages of COPD}

For educational reasons, a simple spirometric classification of disease severity into four stages is recommended (Table 2). Spirometry is essential for diagnosis and provides a useful description of the severity of pathologic changes in COPD. Specific spirometric cut points (e.g., post-bronchodilator $\mathrm{FEV}_{1}$ / FVC ratio $<0.70$ or $\mathrm{FEV}_{1}<80,50$, or $30 \%$ predicted) are used for purposes of simplicity; these cut points have not been clinically validated. A study in a random population sample found that the post-bronchodilator $\mathrm{FEV}_{1} / \mathrm{FVC}$ exceeded 0.70 in all age groups, supporting the use of this fixed ratio (6). However, because the process of aging does affect lung volumes, the use of this fixed ratio may result in overdiagnosis of COPD in the elderly, especially in those with mild disease.

The characteristic symptoms of COPD are chronic and progressive dyspnea, cough, and sputum production. Chronic cough and sputum production may precede the development of airflow limitation by many years. This pattern offers a unique opportunity to identify smokers and others at risk for COPD, and to intervene when the disease is not yet a major health problem. Conversely, significant airflow limitation may develop without chronic cough and sputum production.

Stage I: mild COPD: Characterized by mild airflow limitation $\left(\mathrm{FEV}_{1} / \mathrm{FVC}<0.70, \mathrm{FEV}_{1} \geqslant 80 \%\right.$ predicted). Symptoms of chronic cough and sputum production may be present, but not always. At this stage, the individual is usually unaware that his or her lung function is abnormal.

Stage II: moderate COPD: Characterized by worsening airflow limitation $\left(\mathrm{FEV}_{1} / \mathrm{FVC}<0.70,50 \% \leqslant \mathrm{FEV}_{1}<80 \%\right.$ predicted), with shortness of breath typically developing on exertion and cough and sputum production sometimes also present. This is the stage at which patients typically seek medical attention because of chronic respiratory symptoms or an exacerbation of their disease.

Stage III: severe COPD: Characterized by further worsening of airflow limitation $\left(\mathrm{FEV}_{1} / \mathrm{FVC}<0.70,30 \% \leqslant \mathrm{FEV}_{1}<50 \%\right.$ predicted), greater shortness of breath, reduced exercise capacity, fatigue, and repeated exacerbations that almost always have an impact on patients' quality of life.

TABLE 1. DESCRIPTION OF LEVELS OF EVIDENCE

\begin{tabular}{|c|c|c|}
\hline $\begin{array}{l}\text { Evidence } \\
\text { Category }\end{array}$ & Sources of Evidence & Definition \\
\hline A & RCTs. Rich body of data. & $\begin{array}{l}\text { Evidence is from endpoints of well-designed RCTs that provide a consistent pattern of findings } \\
\text { in the population for which the recommendation is made. Category A requires substantial numbers } \\
\text { of studies involving substantial numbers of participants. }\end{array}$ \\
\hline B & RCTs. Limited body of data. & $\begin{array}{l}\text { Evidence is from endpoints of intervention studies that include only a limited number of patients, } \\
\text { post hoc or subgroup analysis of RCTs, or meta-analysis of RCTs. In general, category B pertains } \\
\text { when few randomized trials exist, they are small in size, they were undertaken in a population } \\
\text { that differs from the target population of the recommendation, or the results are somewhat } \\
\text { inconsistent. }\end{array}$ \\
\hline C & $\begin{array}{l}\text { Nonrandomized trials. } \\
\text { Observational studies. }\end{array}$ & Evidence is from outcomes of uncontrolled or nonrandomized trials or from observational studies. \\
\hline D & Panel consensus judgment. & $\begin{array}{l}\text { This category is used only in cases where the provision of some guidance was deemed valuable but } \\
\text { the clinical literature addressing the subject was insufficient to justify placement in one of the } \\
\text { other categories. The panel consensus is based on clinical experience or knowledge that does not } \\
\text { meet the above-listed criteria. }\end{array}$ \\
\hline
\end{tabular}

Definition of abbreviation: $\mathrm{RCT}=$ randomized controlled trial. 
TABLE 2. SPIROMETRIC CLASSIFICATION OF CHRONIC OBSTRUCTIVE PULMONARY DISEASE SEVERITY BASED ON POST-BRONCHODILATOR FEV

\begin{tabular}{ll}
\hline Stage I: mild & $\mathrm{FEV}_{1} / \mathrm{FVC}<0.70$ \\
& $\mathrm{FEV}_{1} \geqslant 80 \%$ predicted \\
Stage II: moderate & $\mathrm{FEV}_{1} / \mathrm{FVC}<0.70$ \\
& $50 \% \leqslant \mathrm{FEV}_{1}<80 \%$ predicted \\
Stage III: severe & $\mathrm{FEV}_{1} / \mathrm{FVC}<0.70$ \\
& $30 \% \leqslant \mathrm{FEV} \mathrm{F}_{1}<50 \%$ predicted \\
Stage IV: very severe & $\mathrm{FEV}_{1} / \mathrm{FVC}<0.70$ \\
& $\mathrm{FEV}_{1}<30 \%$ predicted or $\mathrm{FEV}_{1}<50 \%$ \\
& predicted plus chronic respiratory failure*
\end{tabular}

* Respiratory failure: arterial partial pressure of oxygen $\left(\mathrm{Pa}_{\mathrm{O}_{2}}\right)<8.0 \mathrm{kPa}$ $(60 \mathrm{~mm} \mathrm{Hg})$ with or without arterial partial pressure of $\mathrm{CO}_{2}\left(\mathrm{~Pa}_{\mathrm{CO}_{2}}\right)>6.7 \mathrm{kPa}$ $(50 \mathrm{~mm} \mathrm{Hg}$ ) while breathing air at sea level.

Stage IV: very severe COPD: Characterized by severe airflow limitation $\left(\mathrm{FEV}_{1} / \mathrm{FVC}<0.70, \mathrm{FEV}_{1}<30 \%\right.$ predicted or $\mathrm{FEV}_{1}<50 \%$ predicted plus the presence of chronic respiratory failure). Respiratory failure is defined as an arterial partial pressure of $\mathrm{O}_{2}\left(\mathrm{~Pa}_{\mathrm{O}_{2}}\right)$ less than $8.0 \mathrm{kPa}(60 \mathrm{~mm} \mathrm{Hg})$, with or without an arterial partial pressure of $\mathrm{CO}_{2}\left(\mathrm{~Pa}_{\mathrm{CO}_{2}}\right)$ greater than $6.7 \mathrm{kPa}(50 \mathrm{~mm} \mathrm{Hg})$ while breathing air at sea level. Respiratory failure may also lead to effects on the heart such as cor pulmonale (right heart failure). Clinical signs of cor pulmonale include elevation of the jugular venous pressure and pitting ankle edema. Patients may have stage IV COPD even if their $\mathrm{FEV}_{1}$ is greater than $30 \%$ predicted, whenever these complications are present. At this stage, quality of life is very appreciably impaired and exacerbations may be life threatening.

Although asthma can usually be distinguished from COPD, in some individuals with chronic respiratory symptoms and fixed airflow limitation it remains difficult to differentiate the two diseases. In many developing countries, both pulmonary tuberculosis and COPD are common (7). In countries where tuberculosis is very common, respiratory abnormalities may be too readily attributed to this disease (8). Conversely, where the rate of tuberculosis is greatly diminished, the possible diagnosis of this disease is sometimes overlooked. Therefore, in all subjects with symptoms of COPD, a possible diagnosis of tuberculosis should be considered, especially in areas where this disease is known to be prevalent (9).

\section{Pathology, Pathogenesis, and Pathophysiology}

Pathologic changes characteristic of COPD are found in the proximal airways, peripheral airways, lung parenchyma, and pulmonary vasculature (10). The pathologic changes include chronic inflammation, with increased numbers of specific inflammatory cell types in different parts of the lung, and structural changes resulting from repeated injury and repair. In general, the inflammatory and structural changes in the airways increase with disease severity and persist on smoking cessation.

The inflammation in the respiratory tract of patients with COPD appears to be an amplification of the normal inflammatory response of the respiratory tract to chronic irritants such as cigarette smoke. The mechanisms for this amplification are not yet understood but may be genetically determined. Some patients develop COPD without smoking, but the nature of the inflammatory response in these patients is unknown (11). Lung inflammation is further amplified by oxidative stress and an excess of proteinases in the lung. Together, these mechanisms lead to the characteristic pathologic changes in COPD.
There is now a good understanding of how the underlying disease process in COPD leads to the characteristic physiologic abnormalities and symptoms. For example, decreased $\mathrm{FEV}_{1}$ primarily results from inflammation and narrowing of peripheral airways and a dynamic airway collapse in more severe emphysema, whereas decreased gas transfer arises from the parenchymal destruction of emphysema. The extent of inflammation, fibrosis, and luminal exudates in small airways is correlated with the reduction in $\mathrm{FEV}_{1}$ and $\mathrm{FEV}_{1} / \mathrm{FVC}$ ratio, and probably with the accelerated decline in $\mathrm{FEV}_{1}$ characteristic of COPD (4). Gas exchange abnormalities result in hypoxemia and hypercapnia, and have several mechanisms in COPD. In general, gas transfer worsens as the disease progresses. Mild to moderate pulmonary hypertension may develop late in the course of COPD and is due to hypoxic vasoconstriction of small pulmonary arteries. It is increasingly recognized that COPD involves several systemic features, particularly in patients with severe disease, and that these have a major impact on survival and comorbid diseases $(12,13)$.

\section{BURDEN OF COPD}

COPD prevalence, morbidity, and mortality vary across countries and across different groups within countries but, in general, are directly related to the prevalence of tobacco smoking, although, in many countries, air pollution resulting from the burning of wood and other biomass fuels has also been identified as a COPD risk factor. The prevalence and burden of COPD are projected to increase in the coming decades due to continued exposure to COPD risk factors and the changing age structure of the world's population.

\section{Epidemiology}

In the past, imprecise and variable definitions of COPD have made it difficult to quantify prevalence, morbidity, and mortality. Furthermore, the underrecognition and underdiagnosis of COPD lead to significant underreporting. The extent of the underreporting varies across countries and depends on the level of awareness and understanding of COPD among health professionals, the organization of health care services to cope with chronic diseases, and the availability of medications for the treatment of COPD (14).

Prevalence. Many sources of variation can affect estimates of COPD prevalence, including sampling methods, response rates, quality control of spirometry, and whether spirometry is performed pre- or post-bronchodilator. Despite these complexities, data are emerging that enable some conclusions to be drawn regarding COPD prevalence. A prevalence study in Latin America (19), a systematic review and meta-analysis of studies performed in 28 countries between 1990 and 2004 (15), and an additional study from Japan (16) provide evidence that the prevalence of COPD (stage I, mild COPD and higher) is appreciably higher in smokers and ex-smokers compared with nonsmokers, in those older than 40 years compared with those younger than 40 years, and in men compared with women.

Morbidity. Morbidity measures traditionally include physician visits, emergency department visits, and hospitalizations. Although COPD databases for these outcome parameters are less readily available and usually less reliable than mortality databases, the limited data available indicate that morbidity due to COPD increases with age and is greater in men than in women $(17,18)$. COPD in its early stages (stages I and II) is usually not recognized, diagnosed, or treated, and therefore may not be included as a diagnosis in a patient's medical record.

Morbidity from COPD may be affected by other comorbid chronic conditions (20) (e.g., musculoskeletal disease, diabetes 
mellitus) that are not directly related to COPD but nevertheless may have an impact on the patient's health status, or may interfere with COPD management. In patients with more advanced disease (stages III and IV), morbidity from COPD may be misattributed to another comorbid condition.

Mortality. COPD is one of the most important causes of death in most countries. The Global Burden of Disease Study $(2,21,22)$ has projected that COPD, which ranked sixth as the cause of death in 1990, will become the third leading cause of death worldwide by 2020 . This increased mortality is driven by the expanding epidemic of smoking and the changing demographics in most countries, with more of the population living longer.

\section{Economic and Social Burden of COPD}

COPD is a costly disease. In developed countries, exacerbations of COPD account for the greatest burden on the health care system. In the European Union, the total direct costs of respiratory disease are estimated to be about $6 \%$ of the total health care budget, with COPD accounting for 56\% (€38.6 billion) of this cost of respiratory disease (23). In the United States in 2002, the direct costs of COPD were $\$ 18$ billion and the indirect costs totaled $\$ 14.1$ billion (1). Costs per patient will vary across countries because these costs depend on how health care is provided and paid (24). Not surprisingly, there is a striking direct relationship between the severity of COPD and the cost of care (25), and the distribution of costs changes as the disease progresses.

\section{Risk Factors}

Identification of cigarette smoking as the most commonly encountered risk factor for COPD has led to the incorporation of smoking cessation programs as a key element of COPD prevention, as well as an important intervention for patients who already have the disease. However, although smoking is the best-studied COPD risk factor, it is not the only one and there is consistent evidence from epidemiologic studies that nonsmokers may develop chronic airflow obstruction $(26,27)$ (Figure 1).

Genes. As the understanding of the importance of risk factors for COPD has grown, so has the recognition that essentially all risk for COPD results from a gene-environment interaction. The genetic risk factor that is best documented is a severe hereditary deficiency of $\alpha_{1}$-antitrypsin (28), a major circulating inhibitor of serine proteases. This rare recessive trait is most commonly seen in individuals of northern European origin (29).

Genetic association studies have implicated a variety of genes in COPD pathogenesis. However, the results of these genetic association studies have been largely inconsistent, and functional genetic variants influencing the development of COPD (other than $\alpha_{1}$-antitrypsin deficiency) have not been definitively identified (30).

Inhalational exposures. ТОВАССО SмОке. Cigarette smokers have a higher prevalence of respiratory symptoms and lung function abnormalities, a greater annual rate of decline in $\mathrm{FEV}_{1}$, and a greater COPD mortality rate than nonsmokers. Pipe and cigar smokers have greater COPD morbidity and mortality rates than nonsmokers, although their rates are lower than those for cigarette smokers (31). Other types of tobacco smoking popular in various countries are also risk factors for COPD $(32,33)$. Not all smokers develop clinically significant COPD, which suggests that genetic factors must modify each individual's risk (34). Passive exposure to cigarette smoke may also contribute to respiratory symptoms (35) and COPD (36) by increasing the lungs' total burden of inhaled particles and gases $(37,38)$. Smoking during pregnancy may also pose a risk for the fetus, by affecting lung growth and development in utero and possibly the priming of the immune system $(39,40)$.

OCCUPATIONAL DUSTS AND CHEMICALS. Occupational exposures include organic and inorganic dusts and chemical agents and fumes. A statement published by the American Thoracic Society concluded that occupational exposures account for 10 to $20 \%$ of either symptoms or functional impairment consistent with COPD (41).

INDOOR AND OUTDOOR AIR POLLUTION. The evidence that indoor pollution from biomass cooking and heating in poorly ventilated dwellings is an important risk factor for COPD (especially among women in developing countries) continues to grow (42-48), with case-control studies $(47,48)$ and other designed studies now available. High levels of urban air pollution are harmful to individuals with existing heart or lung disease, but the role of outdoor air pollution in causing COPD is unclear.

Sex. Studies from developed countries $(1,49)$ show that the prevalence of the disease is now almost equal in men and

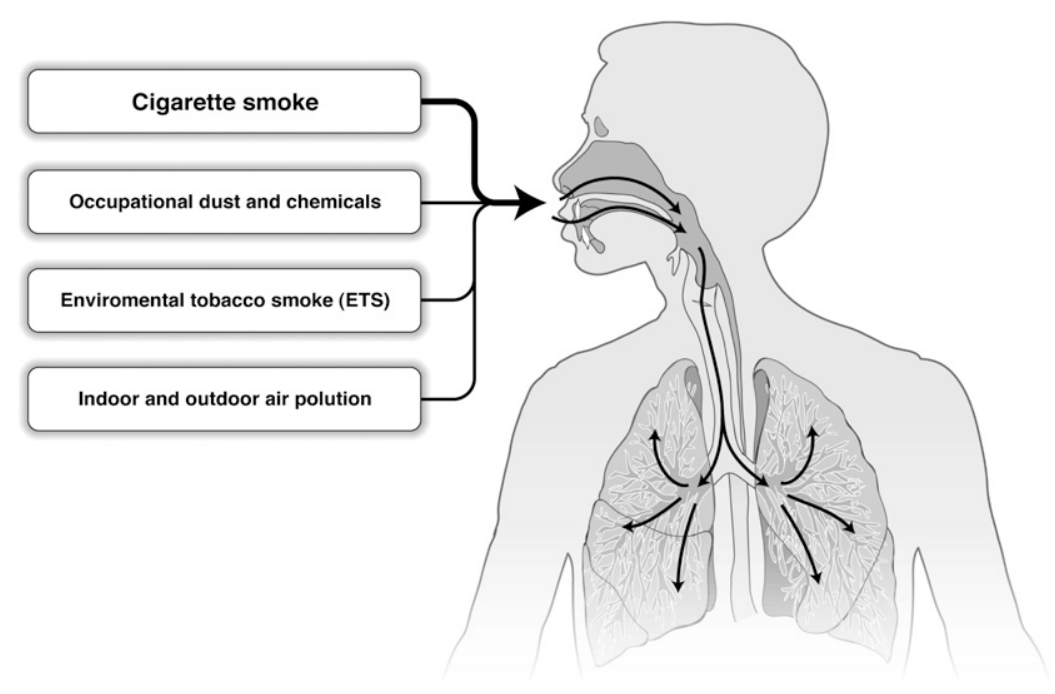

Figure 1. Chronic obstructive pulmonary disease risk is related to the total burden of inhaled particles. 
women, probably reflecting the changing patterns of tobacco smoking. Some studies have suggested that women are more susceptible to the effects of tobacco smoke than men (5052).

Infection. A history of severe childhood respiratory infection has been associated with reduced lung function and increased respiratory symptoms in adulthood (53-55). However, susceptibility to viral infections may be related to another factor, such as low birth weight, that itself is related to COPD.

Socioeconomic status. There is evidence that the risk of developing COPD is inversely related to socioeconomic status (56). It is not clear, however, whether this pattern reflects exposures to cigarette smoke, indoor and outdoor air pollutants, crowding, poor nutrition, or other factors that are related to low socioeconomic status $(57,58)$.

\section{THE FOUR COMPONENTS OF COPD MANAGEMENT}

\section{Introduction}

An effective COPD management plan includes four components: (1) assess and monitor disease, (2) reduce risk factors, (3) manage stable COPD, and (4) manage exacerbations. Although disease prevention is the ultimate goal, once COPD has been diagnosed, effective management should be aimed at the following goals:

- Relieve symptoms

- Prevent disease progression

- Improve exercise tolerance

- Improve health status

- Prevent and treat complications

- Prevent and treat exacerbations

- Reduce mortality

These goals should be reached with minimal side effects from treatment, a particular challenge in patients with COPD because they commonly have comorbidities. The extent to which these goals can be realized varies with each individual, and some treatments will produce benefits in more than one area. In selecting a treatment plan, the benefits and risks to the individual, and the costs, direct and indirect, to the individual, his or her family, and the community must be considered.

Patients should be identified as early in the course of the disease as possible, and certainly before the end stage of the illness when disability is substantial. Access to spirometry is key to the diagnosis of COPD and should be available to health care workers who care for patients with COPD. However, the benefits of community-based spirometric screening, of either the general population or smokers, are still unclear.

Educating patients, physicians, and the public to recognize that cough, sputum production, and especially breathlessness are not trivial symptoms is an essential aspect of the public health care of this disease.

Reduction of therapy once symptom control has been achieved is not normally possible in COPD. Further deterioration of lung function usually requires the progressive introduction of more treatments, both pharmacologic and nonpharmacologic, to attempt to limit the impact of these changes. Exacerbations of signs and symptoms, a hallmark of COPD, impair patients' quality of life and decrease their health status. Appropriate treatment and measures to prevent further exacerbations should be implemented as quickly as possible.

\section{Component 1: Assess and Monitor Disease}

\section{KEY POINTS}

- A clinical diagnosis of COPD should be considered in any patient who has dyspnea, chronic cough or sputum production, and/or a history of exposure to risk factors for the disease. The diagnosis should be confirmed by spirometry.

- For the diagnosis and assessment of COPD, spirometry is the gold standard because it is the most reproducible, standardized, and objective way of measuring airflow limitation. A post-bronchodilator $\mathrm{FEV}_{1} / \mathrm{FVC}<0.70$ confirms the presence of airflow limitation that is not fully reversible.

- Health care workers involved in the diagnosis and management of patients with COPD should have access to spirometry.

- Assessment of COPD severity is based on the patient's level of symptoms, the severity of the spirometric abnormality, and the presence of complications.

- Measurement of arterial blood gas tensions should be considered in all patients with $\mathrm{FEV}_{1}<50 \%$ predicted or clinical signs suggestive of respiratory failure or right heart failure.

- COPD is usually a progressive disease and lung function can be expected to worsen over time, even with the best available care. Symptoms and objective measures of airflow limitation should be monitored to determine when to modify therapy and to identify any complications that may develop.

- Comorbidities are common in COPD and should be actively identified. Comorbidities often complicate the management of COPD, and vice versa.

Initial diagnosis. A clinical diagnosis of COPD should be considered in any patient who has dyspnea, chronic cough or sputum production, and/or a history of exposure to risk factors for the disease (Table 3 ). The diagnosis should be confirmed by spirometry.

AsSESSMENT OF SYMPTOMS. Dyspnea, the hallmark symptom of COPD, is the reason most patients seek medical attention and is a major cause of disability and anxiety associated with the disease. As lung function deteriorates, breathlessness becomes more intrusive. Chronic cough, often the first symptom of COPD to develop (59) and often predating the onset of dyspnea, may be intermittent, but later is present every day, often throughout the day. In some cases, significant airflow limitation may develop without the presence of a cough. Patients with COPD commonly raise small quantities of tenacious sputum after coughing bouts. Wheezing and chest tightness are nonspecific symptoms that may vary between days, and over the course of a single day. An absence of wheezing or chest tightness does not exclude a diagnosis of COPD. Weight loss, anorexia, and psychiatric morbidity, especially symptoms of depression and/or anxiety, are common problems in advanced COPD $(60,61)$.

Medical history. A detailed medical history of a new patient known or believed to have COPD should assess the following:

- Exposure to risk factors 
TABLE 3. KEY INDICATORS FOR CONSIDERING A DIAGNOSIS OF CHRONIC OBSTRUCTIVE PULMONARY DISEASE

Consider COPD, and perform spirometry, if any of these indicators are present in an individual. These indicators are not diagnostic themselves, but the presence of multiple key indicators increases the probability of a diagnosis of COPD. Spirometry is needed to establish a diagnosis of COPD.

Dyspnea that is

Progressive (worsens over time)

Usually worse with exercise

Persistent (present every day)

Described by the patient as an "increased effort to breathe," "heaviness," "air hunger," or "gasping

Chronic cough May be intermittent and may be unproductive

Chronic sputum production Any pattern of chronic sputum production may indicate COPD

History of exposure Tobacco smoke

to risk factors, especially, Occupational dusts and chemicals

Smoke from home cooking and heating fuels

Definition of abbreviation: COPD = chronic obstructive pulmonary disease.

- Past medical history, including asthma, allergy, sinusitis, or nasal polyps; respiratory infections in childhood; other respiratory diseases

- Family history of COPD or other chronic respiratory disease

- Pattern of symptom development

- History of exacerbations or previous hospitalizations for respiratory disorder

- Presence of comorbidities, such as heart disease, malignancies, osteoporosis, and muscloskeletal disorders, which may also contribute to restriction of activity (62)

- Appropriateness of current medical treatments

- Impact of disease on patient's life, including limitation of activity, missed work and economic impact, effect on family routines, feelings of depression or anxiety

- Social and family support available to the patient

- Possibilities for reducing risk factors, especially smoking cessation

Physical examination. Although an important part of patient care, a physical examination is rarely diagnostic in COPD. Physical signs of airflow limitation are usually not present until significant impairment of lung function has occurred (63, 64 ), and their detection has a relatively low sensitivity and specificity.

Measurement of Airflow limitation (SPIROMETRy). Spirometry should be undertaken in all patients who may have COPD. Spirometry should measure the volume of air forcibly exhaled from the point of maximal inspiration (FVC) and the volume of air exhaled during the first second of this maneuver $\left(\mathrm{FEV}_{1}\right)$, and the ratio of these two measurements $\left(\mathrm{FEV}_{1} / \mathrm{FVC}\right)$ should be calculated. Spirometry measurements are evaluated by comparison with reference values (65) based on age, height, sex, and race (use appropriate reference values; e.g., see Reference 65). Patients with COPD typically show a decrease in both $\mathrm{FEV}_{1}$ and FVC. The presence of airflow limitation is defined by a post-bronchodilator $\mathrm{FEV}_{1} / \mathrm{FVC}<0.70$. This approach is pragmatic in view of the fact that universally applicable reference values for $\mathrm{FEV}_{1}$ and FVC are not available. Where possible, values should be compared with age-related normal values to avoid overdiagnosis of COPD in the elderly (66). Using the fixed ratio $\left(\mathrm{FEV}_{1} / \mathrm{FVC}\right)$ is particularly problematic in patients with milder COPD who are elderly because the normal process of aging affects lung volumes.

Assessment OF COPD SEVERITY. Assessment of COPD severity is based on the patient's level of symptoms, the severity of the spirometric abnormality (Table 2), and the presence of complications such as respiratory failure, right heart failure, weight loss, and arterial hypoxemia.

Additional investigations. For patients diagnosed with stage II, moderate, COPD and beyond, the following additional investigations may be considered.

Bronchodilator reversibility testing. Despite earlier hopes, neither bronchodilator nor oral glucocorticosteroid reversibility testing predicts disease progression, whether judged by decline in $\mathrm{FEV}_{1}$, deterioration of health status, or frequency of exacerbations $(67,68)$ in patients with a clinical diagnosis of COPD and abnormal spirometry (68). In some cases (e.g., a patient with an atypical history such as asthma in childhood and regular night waking with cough or wheeze), a clinician may wish to perform a bronchodilator and/or glucocorticosteroid reversibility test.

Chest $X$-ray. An abnormal chest X-ray is seldom diagnostic in COPD unless obvious bullous disease is present, but it is valuable in excluding alternative diagnoses and establishing the presence of significant comorbidities, such as cardiac failure. Computed tomography (CT) of the chest is not routinely recommended. However, when there is doubt about the diagnosis of COPD, high-resolution CT scanning might help in the differential diagnosis. In addition, if a surgical procedure such as lung volume reduction is contemplated, a chest CT scan is necessary because the distribution of emphysema is one of the most important determinants of surgical suitability (69).

Arterial blood gas measurement. In advanced COPD, measurement of arterial blood gases while the patient is breathing air is important. This test should be performed in stable patients with $\mathrm{FEV}_{1}<50 \%$ predicted or with clinical signs suggestive of respiratory failure or right heart failure.

$\alpha_{1}$-Antitrypsin deficiency screening. In patients of Caucasian descent who develop COPD at a young age $(<45 \mathrm{yr})$ or who have a strong family history of the disease, it may be valuable to identify coexisting $\alpha_{1}$-antitrypsin deficiency. This could lead to family screening or appropriate counseling.

DiFFERENTIAL DIAGNOSIS. In some patients with chronic asthma, a clear distinction from COPD is not possible using current imaging and physiologic testing techniques, and it is assumed that asthma and COPD coexist in these patients. In these cases, current management is similar to that of asthma. Other potential diagnoses are usually easier to distinguish from COPD (Table 4).

Ongoing monitoring and assessment. MONITOR DISEASE PROGRESSION AND DEVELOPMENT OF COMPLICATIONS. COPD is usually a progressive disease. Lung function can be expected to worsen over time, even with the best available care. Symptoms and objective measures of airflow limitation should be monitored to determine when to modify therapy and to identify any complications that may develop.

Follow-up visits should include a physical examination and discussion of symptoms, particularly any new or worsening symptoms. Spirometry should be performed if there is a substantial increase in symptoms or a complication. The development of respiratory failure is indicated by a $\mathrm{Pa}_{\mathrm{O}_{2}}<8.0 \mathrm{kPa}(60$ $\mathrm{mm} \mathrm{Hg})$ with or without $\mathrm{Pa}_{\mathrm{CO}_{2}}>6.7 \mathrm{kPa}(50 \mathrm{~mm} \mathrm{Hg})$ in arterial blood gas measurements made while breathing air at sea level. Measurement of pulmonary arterial pressure is not recommended in clinical practice as it does not add practical information beyond that obtained from a knowledge of $\mathrm{Pa}_{\mathrm{O}_{2}}$. 
MONITOR PHARMACOTHERAPY AND OTHER MEDICAL TREATMENT. To adjust therapy appropriately as the disease progresses, each follow-up visit should include a discussion of the current therapeutic regimen. Dosages of various medications, adherence to the regimen, inhaler technique, effectiveness of the current regime at controlling symptoms, and side effects of treatment should be monitored.

Monitor eXACERBATION HISTORY. Frequency, severity, and likely causes of exacerbations should be evaluated. Increased sputum volume, acutely worsening dyspnea, and the presence of purulent sputum should be noted. Severity can be estimated by the increased need for bronchodilator medication or glucocorticosteroids and by the need for antibiotic treatment. Hospitalizations should be documented, including the facility, duration of stay, and any use of critical care or intubation.

Monitor COMORBIDITIEs. Comorbidities are common in COPD and may become harder to manage when COPD is present, either because COPD adds to the total level of disability or because COPD therapy adversely affects the comorbid disorder. Until more integrated guidance about disease management for specific comorbid problems becomes available, the focus should be on identification and management of these individual problems.

\section{Component 2: Reduce Risk Factors}

\section{KEY POINTS}

- Reduction of total personal exposure to tobacco smoke, occupational dusts and chemicals, and indoor and outdoor air pollutants are important goals to prevent the onset and progression of COPD.

- Smoking cessation is the single most effective-and costeffective-intervention in most people to reduce the risk of developing COPD and stop its progression (Evidence $\mathbf{A}$ ).

- Comprehensive tobacco control policies and programs with clear, consistent, and repeated nonsmoking messages should be delivered through every feasible channel.

- Efforts to reduce smoking through public health initiatives should also focus on passive smoking to minimize risks for nonsmokers.

- Many occupationally induced respiratory disorders can be reduced or controlled through a variety of strategies aimed at reducing the burden of inhaled particles and gases.

- Reducing the risk from indoor and outdoor air pollution is feasible and requires a combination of public policy and protective steps taken by individual patients.
TABLE 4. DIFFERENTIAL DIAGNOSIS OF CHRONIC OBSTRUCTIVE PULMONARY DISEASE

\begin{tabular}{|c|c|}
\hline Diagnosis & Suggestive Features \\
\hline \multirow[t]{5}{*}{ COPD } & Onset in midlife \\
\hline & Symptoms slowly progressive \\
\hline & Long history of tobacco smoking \\
\hline & Dyspnea during exercise \\
\hline & Largely irreversible airflow limitation \\
\hline \multirow[t]{6}{*}{ Asthma } & Onset early in life (often childhood) \\
\hline & Symptoms vary from day to day \\
\hline & Symptoms at night/early morning \\
\hline & Allergy, rhinitis, and/or eczema also present \\
\hline & Family history of asthma \\
\hline & Largely reversible airflow limitation \\
\hline \multirow[t]{3}{*}{ Congestive heart failure } & Nonspecific basilar crackles on auscultation \\
\hline & Chest X-ray shows dilated heart, pulmonary edema \\
\hline & $\begin{array}{l}\text { Pulmonary function tests indicate volume } \\
\text { restriction, not airflow limitation }\end{array}$ \\
\hline \multirow[t]{4}{*}{ Bronchiectasis } & Large volumes of purulent sputum \\
\hline & Commonly associated with bacterial infection \\
\hline & Coarse crackles/clubbing on auscultation \\
\hline & $\begin{array}{l}\text { Chest } \mathrm{X} \text {-ray/CT shows bronchial dilation, } \\
\text { bronchial wall thickening }\end{array}$ \\
\hline \multirow[t]{4}{*}{ Tuberculosis } & Onset all ages \\
\hline & Chest X-ray shows lung infiltrate \\
\hline & Microbiological confirmation \\
\hline & High local prevalence of tuberculosis \\
\hline \multirow[t]{3}{*}{ Obliterative bronchiolitis } & Onset in younger age, nonsmokers \\
\hline & $\begin{array}{l}\text { May have history of rheumatoid arthritis } \\
\text { or fume exposure }\end{array}$ \\
\hline & CT on expiration shows hypodense areas \\
\hline \multirow[t]{3}{*}{ Diffuse panbronchiolitis } & Most patients are male and nonsmokers \\
\hline & Almost all have chronic sinusitis \\
\hline & $\begin{array}{l}\text { Chest X-ray and HRCT show diffuse small } \\
\text { centrilobular nodular opacities and hyperinflation }\end{array}$ \\
\hline
\end{tabular}

Definition of abbreviations: COPD = chronic obstructive pulmonary disease; $\mathrm{CT}=$ computed tomography; $\mathrm{HRCT}=$ high-resolution computed tomography.

These features tend to be characteristic of the respective diseases, but do not occur in every case. For example, a person who has never smoked may develop COPD (especially in the developing world where other risk factors may be more important than cigarette smoking); asthma may develop in adult and even elderly patients.
Smoking prevention and cessation. Comprehensive tobacco control policies and programs with clear, consistent, and repeated nonsmoking messages should be delivered through every feasible channel, including health care providers, community activities, and schools, and radio, television, and print media. Legislation to establish smoke-free schools, public facilities, and work environments should be developed and implemented by government officials and public health workers, and encouraged by the public.

SMOKIng CESSATION inTERVENTION PROCESS. Smoking cessation is the single most effective - and cost-effective-way to reduce exposure to COPD risk factors. All smokers-including those who may be at risk for COPD as well as those who already have the disease-should be offered the most intensive smoking cessation intervention feasible. Even a brief $(3 \mathrm{~min})$ period of counseling to urge a smoker to quit results in smoking cessation rates of 5 to $10 \%$ (70). At the very least, this should be done for every smoker at every health care provider visit $(70,71)$.

Guidelines for smoking cessation entitled "Treating Tobacco Use and Dependence: A Clinical Practice Guideline" were published by the U.S. Public Health Service (72) and recommend a five-step program for intervention (Table 5), which provides a strategic framework helpful to health care providers interested in helping their patients stop smoking (72-75).

Pharmacotherapy. Numerous effective pharmacotherapies for smoking cessation now exist $(72,73,76)$ (Evidence A), and pharmacotherapy is recommended when counseling is not sufficient to help patients quit smoking. Numerous studies indicate that nicotine replacement therapy in any form (nicotine gum, inhaler, nasal spray, transdermal patch, sublingual tablet, or lozenge) reliably increases long-term smoking abstinence rates $(72,77)$.

The antidepressants bupropion (78) and nortriptyline have also been shown to increase long-term quit rates $(76,77,79)$, but should always be used as one element in a supportive intervention program rather than on their own. The effectiveness of the antihypertensive drug clonidine is limited by side effects (77). Varenicline, a nicotinic acetylcholine receptor partial 
agonist that aids smoking cessation by relieving nicotine withdrawal symptoms and reducing the rewarding properties of nicotine, has been demonstrated to be safe and efficacious (8082). Special consideration should be given before using pharmacotherapy in the following selected populations: people with medical contraindications, light smokers ( $<10$ cigarettes/d), and pregnant and adolescent smokers.

Occupational exposures. Although it is not known how many individuals are at risk of developing respiratory disease from occupational exposures in either developing or developed countries, many occupationally induced respiratory disorders can be reduced or controlled through a variety of strategies aimed at reducing the burden of inhaled particles and gases (83-85).

The main emphasis should be on primary prevention, which is best achieved by the elimination or reduction of exposures to various substances in the workplace. Secondary prevention, achieved through surveillance and early case detection, is also of great importance.

Indoor and outdoor air pollution. Individuals experience diverse indoor and outdoor environments throughout the day, each of which has its own unique set of air contaminants and particulates that cause adverse effects on lung function (86). Although outdoor and indoor air pollution are generally considered separately, the concept of total personal exposure may be more relevant for COPD. Reducing the risk from indoor and outdoor air pollution is feasible and requires a combination of public policy and protective steps taken by individual patients. At the national level, achieving a set level of air quality standards should be a high priority; this goal will normally require legislative action. Reduction of exposure to smoke from biomass fuel, particularly among women and children, is a crucial goal to reduce the prevalence of COPD worldwide. Although efficient nonpolluting cooking stoves have been developed, their adoption has been slow due to social customs and cost.

The health care provider should consider COPD risk factors, including smoking history, family history, exposure to indoor/ outdoor pollution, and socioeconomic status, for each individual patient. Those who are at high risk should avoid vigorous exercise outdoors during pollution episodes. Persons with advanced COPD should monitor public announcements of air quality and be aware that staying indoors when air quality is poor may help reduce their symptoms. If various solid fuels are used for cooking and heating, adequate ventilation should be encouraged. Under most circumstances, vigorous attempts should be made to reduce exposure through reducing workplace

\section{TABLE 5. BRIEF STRATEGIES TO HELP THE PATIENT WHO IS}

\section{WILLING TO QUIT}

1. ASK: Systematically identify all tobacco users at every visit. Implement an officewide system that ensures that, for EVERY patient at EVERY clinic visit, tobacco use status is queried and documented.

2. ADVISE: Strongly urge all tobacco users to quit.

In a clear, strong, and personalized manner, urge every tobacco user to quit.

3. ASSESS: Determine willingness to make a quit attempt.

Ask every tobacco user if he or she is willing to make a quit attempt at this time (e.g., within the next $30 \mathrm{~d}$ ).

4. ASSIST: Aid the patient in quitting.

Help the patient with a quit plan; provide practical counseling; provide intratreatment social support; help the patient obtain extratreatment social support; recommend use of approved pharmacotherapy except in special circumstances; provide supplementary materials.

5. ARRANGE: Schedule follow-up contact.

Schedule follow-up contact, either in person or via telephone.

Data from References $72-75$. emissions and improving ventilation measures, rather than simply using respiratory protection to reduce the risks of ambient air pollution. Air cleaners have not been shown to have health benefits, whether directed at pollutants generated by indoor sources or at those brought in with outdoor air.

\section{Component 3: Manage Stable COPD}

\section{KEY POINTS}

- The overall approach to managing stable COPD should be individualized to address symptoms and improve quality of life.

- For patients with COPD, health education plays an important role in smoking cessation (Evidence A) and can also play a role in improving skills, ability to cope with illness, and health status.

- None of the existing medications for COPD have been shown to modify the long-term decline in lung function that is the hallmark of this disease (Evidence A). Therefore, pharmacotherapy for COPD is used to decrease symptoms and/or complications.

- Bronchodilator medications are central to the symptomatic management of COPD (Evidence A). They are given on an as-needed basis or on a regular basis to prevent or reduce symptoms and exacerbations.

- The principal bronchodilator treatments are $\beta_{2}$-agonists, anticholinergics, and methylxanthines used singly or in combination (Evidence A).

- Regular treatment with long-acting bronchodilators is more effective and convenient than treatment with short-acting bronchodilators (Evidence A).

- The addition of regular treatment with inhaled glucocorticosteroids to bronchodilator treatment is appropriate for symptomatic patients with COPD with an $\mathrm{FEV}_{1}<50 \%$ predicted (stage III, severe COPD, and stage IV, very severe COPD) and repeated exacerbations (Evidence A).

- Chronic treatment with systemic glucocorticosteroids should be avoided because of an unfavorable benefitto-risk ratio (Evidence $\mathrm{A}$ ).

- In patients with COPD, influenza vaccines can reduce serious illness (Evidence A). Pneumococcal polysaccharide vaccine is recommended for patients with COPD who are 65 years and older and for patients with COPD who are younger than age 65 with an $\mathrm{FEV}_{1}<40 \%$ predicted (Evidence B).

- All patients with COPD benefit from exercise training programs, improving with respect to both exercise tolerance and symptoms of dyspnea and fatigue (Evidence A).

- The long-term administration of oxygen $(>15 \mathrm{~h} / \mathrm{d})$ to patients with chronic respiratory failure has been shown to increase survival (Evidence A).

Introduction. The overall approach to managing stable COPD should be characterized by an increase in treatment, depending on the severity of the disease and the clinical status of the patient. Management of COPD is based on an individualized assessment of disease severity and response to various therapies. The classification of severity of stable COPD incorporates an individualized assessment of disease severity and therapeutic response into the management strategy. The severity of airflow limitation provides a general guide to the use of some treatments, but the 
selection of therapy is predominantly determined by the patient's symptoms and clinical presentation. Treatment also depends on the patient's educational level and willingness to apply the recommended management, on cultural and local practice conditions, and on the availability of medications.

Education. Although patient education is generally regarded as an essential component of care for any chronic disease, assessment of the value of education in COPD may be difficult because of the relatively long time required to achieve improvements in objective measurements of lung function. Patient education alone does not improve exercise performance or lung function (87-90) (Evidence B), but it can play a role in improving skills, ability to cope with illness, and health status (91). Patient education regarding smoking cessation has the greatest capacity to influence the natural history of COPD (Evidence A). Education also improves patient response to exacerbations $(92,93)$ (Evidence B). Prospective end-of-life discussions can lead to understanding of advance directives and effective therapeutic decisions at the end of life (94) (Evidence B).

Ideally, educational messages should be incorporated into all aspects of care for COPD and may take place in many settings: consultations with physicians or other health care workers, home-care or outreach programs, and comprehensive pulmonary rehabilitation programs. Education should be tailored to the needs and environment of the individual patient, interactive, directed at improving quality of life, simple to follow, practical, and appropriate to the intellectual and social skills of the patient and the caregivers. The topics that seem most appropriate for an education program include the following: smoking cessation; basic information about COPD and pathophysiology of the disease, general approach to therapy and specific aspects of medical treatment, self-management skills, strategies to help minimize dyspnea, advice about when to seek help, selfmanagement and decision making during exacerbations, and advance directives and end-of-life issues.

Pharmacologic treatments. Pharmacologic therapy is used to prevent and control symptoms (Figure 2), reduce the frequency and severity of exacerbations, improve health status, and improve exercise tolerance. None of the existing medications
(Table 6) for COPD have been shown to modify the long-term decline in lung function that is the hallmark of this disease (51, 95-97) (Evidence A). However, this should not preclude efforts to use medications to control symptoms.

BRONCHODILATORs. Bronchodilator medications are central to the symptomatic management of COPD (98-101) (Evidence A) (Table 7). They are given either on an as-needed basis for relief of persistent or worsening symptoms or on a regular basis to prevent or reduce symptoms. The side effects of bronchodilator therapy are pharmacologically predictable and dose dependent. Adverse effects are less likely, and resolve more rapidly after treatment withdrawal, with inhaled than with oral treatment. When treatment is given by the inhaled route, attention to effective drug delivery and training in inhaler technique are essential.

Bronchodilator drugs commonly used in treating COPD include $\beta_{2}$-agonists, anticholinergics, and methylxanthines. The choice depends on the availability of the medications and the patient's response. All categories of bronchodilators have been shown to increase exercise capacity in COPD, without necessarily producing significant changes in $\mathrm{FEV}_{1}(102-105)$ (Evidence A).

Regular treatment with long-acting bronchodilators is more effective and convenient than treatment with short-acting bronchodilators (106-109) (Evidence A). Regular use of a longacting $\beta_{2}$-agonist (107) or a short- or long-acting anticholinergic improves health status (106-108). Treatment with a long-acting inhaled anticholinergic drug reduces the rate of COPD exacerbations (110) and improves the effectiveness of pulmonary rehabilitation (111). Theophylline is effective in COPD, but, due to its potential toxicity, inhaled bronchodilators are preferred when available. All studies that have shown efficacy of theophylline in COPD were done with slow-release preparations.

Combining bronchodilators with different mechanisms and durations of action may increase the degree of bronchodilation for equivalent or lesser side effects. A combination of a shortacting $\beta_{2}$-agonist and an anticholinergic produces greater and more sustained improvements in $\mathrm{FEV}_{1}$ than either drug alone and does not produce evidence of tachyphylaxis over 90 days of treatment (112-114) (Evidence A).

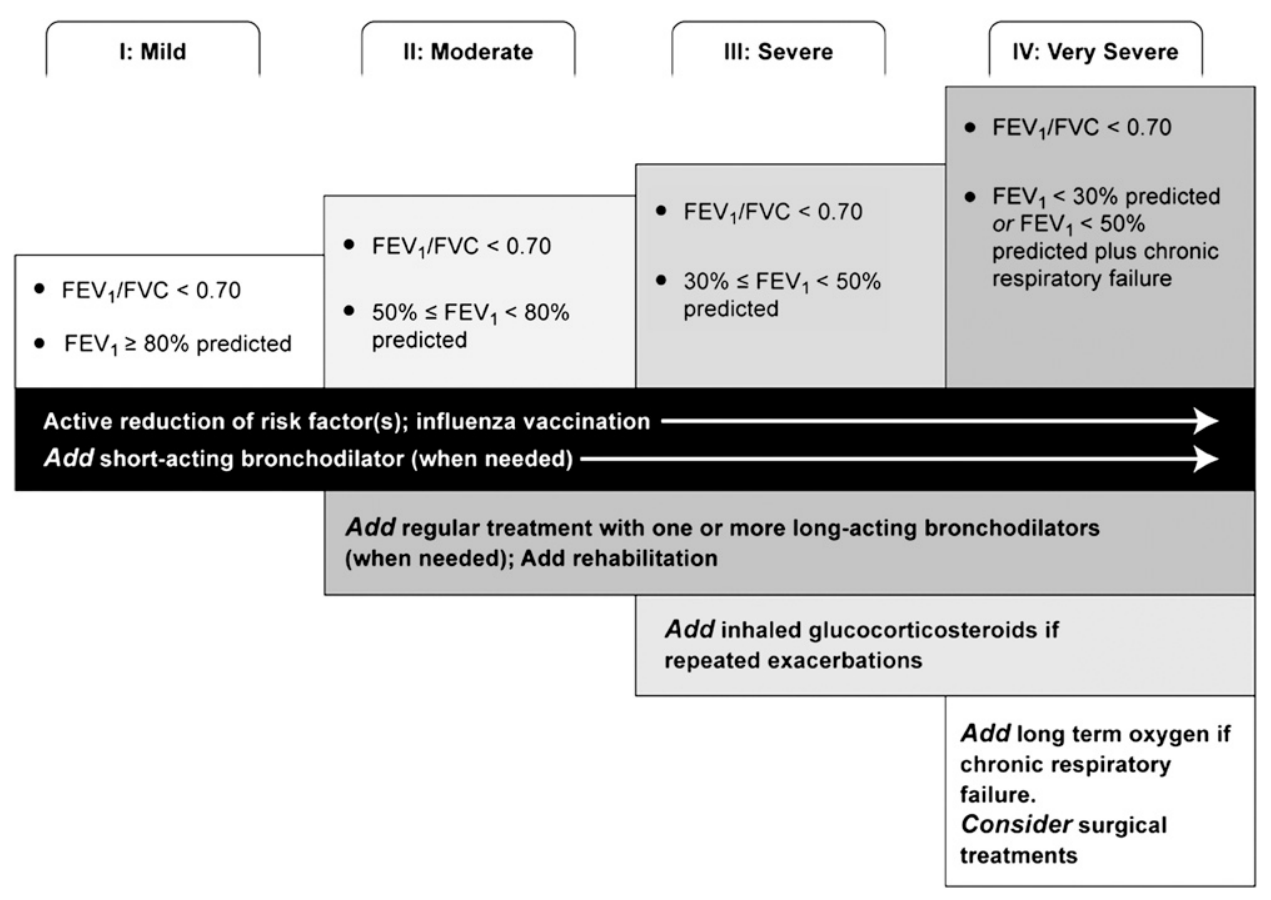

Figure 2. Therapy at each stage of chronic obstructive pulmonary disease (COPD). Post-bronchodilator $\mathrm{FEV}_{1}$ is recommended for the diagnosis and assessment of severity of COPD. 
TABLE 6. COMMONLY USED FORMULATIONS OF MEDICATIONS USED IN CHRONIC OBSTRUCTIVE PULMONARY DISEASE

\begin{tabular}{|c|c|c|c|c|c|}
\hline Medication & Inhaler $(\mu g)$ & $\begin{array}{c}\text { Solution for } \\
\text { Nebulizer }(\mathrm{mg} / \mathrm{ml})\end{array}$ & Oral & $\begin{array}{c}\text { Vials for } \\
\text { Injection }(m g)\end{array}$ & $\begin{array}{l}\text { Duration of } \\
\text { Action }(h)\end{array}$ \\
\hline \multicolumn{6}{|l|}{$\beta_{2}$-Agonists } \\
\hline \multicolumn{6}{|l|}{ Short-acting } \\
\hline Salbutamol (albuterol) & $100,200(\mathrm{MDI}$ and $\mathrm{DPI})$ & 5 & $5 \mathrm{mg}$ (pill) $0.24 \%$ (syrup) & $0.1,0.5$ & $4-6$ \\
\hline Terbutaline & $400,500(\mathrm{DPI})$ & & & $0.2,0.25$ & $4-6$ \\
\hline \multicolumn{6}{|l|}{ Long-acting } \\
\hline \multicolumn{6}{|l|}{ Anticholinergics } \\
\hline \multicolumn{6}{|l|}{ Short-acting } \\
\hline Ipatropium bromide & 20,40 (MDI) & $0.25-0.5$ & & & $6-8$ \\
\hline Oxitropium bromide & $100(\mathrm{MDI})$ & 1.5 & & & $7-9$ \\
\hline \multicolumn{6}{|l|}{ Long-acting } \\
\hline Tiotropium & 18 (DPI) & & & & $24+$ \\
\hline \multicolumn{6}{|l|}{ Combination short-acting } \\
\hline \multicolumn{6}{|l|}{ Methylxanthines } \\
\hline Aminophylline & & & $200-600 \mathrm{mg}$ (pill) & 240 & Variable, up to 24 \\
\hline Theophylline (SR) & & & $100-600 \mathrm{mg}$ (pill) & & Variable, up to 24 \\
\hline \multicolumn{6}{|l|}{ Inhaled glucocorticosteroids } \\
\hline Beclomethasone & 50-400 (MDI and DPI) & $0.2-0.4$ & & & \\
\hline Budesonide & $100,200,400(\mathrm{DPI})$ & $0.20,0.25,0.5$ & & & \\
\hline Fluticasone & $50-500(\mathrm{MDI}$ and $\mathrm{DPI})$ & & & & \\
\hline Triamcinolone & $100(\mathrm{MDI})$ & 40 & & 40 & \\
\hline \multicolumn{6}{|l|}{ Combination long-acting } \\
\hline \multicolumn{6}{|l|}{$\begin{array}{l}\beta_{2} \text {-agonists plus } \\
\text { glucocorticosteroids } \\
\text { in one inhaler }\end{array}$} \\
\hline Formoterol/budesonide & $4.5 / 160,9 / 320(\mathrm{DPI})$ & & & & \\
\hline Salmeterol/fluticasone & $\begin{array}{l}50 / 100,250,500(\mathrm{DPI}) 25 / 50 \\
125,250(\mathrm{MDI})\end{array}$ & & & & \\
\hline
\end{tabular}

Definition of abbreviation: $\mathrm{DPI}=$ dry powder inhaler; $\mathrm{MDI}=$ metered-dose inhaler; $\mathrm{SR}=$ slow release.

The combination of a $\beta_{2}$-agonist, an anticholinergic, and/or theophylline may produce additional improvements in lung function (112-118) and health status $(112,119)$. Increasing the number of drugs usually increases costs, and an equivalent benefit may occur by increasing the dose of one bronchodilator when side effects are not a limiting factor. Detailed assessments of this approach have not been performed.

Dose-response relationships using the $\mathrm{FEV}_{1}$ as the outcome are relatively flat with all classes of bronchodilators (98-101). Toxicity is also dose related. Increasing the dose of either a $\beta_{2}$-agonist or an anticholinergic by an order of magnitude, especially when given by a wet nebulizer, appears to provide subjective benefit in acute episodes (120) (Evidence B) but is not necessarily helpful in stable disease (121) (Evidence C).

When treatment is given by the inhaled route, attention to effective drug delivery and training in inhaler technique are essential. The choice of inhaler device will depend on availability, cost, the prescribing physician, and the skills and ability of the patient. Patients with COPD may have more problems in effective coordination and find it harder to use a simple metereddose inhaler than do healthy volunteers or younger patients with asthma. It is essential to ensure that inhaler technique is correct and to recheck this at each visit.

Glucocorticosteroids. Regular treatment with inhaled glucocorticosteroids does not modify the long-term decline of $\mathrm{FEV}_{1}$ in patients with COPD $(95-97,122)$. However, regular treatment with inhaled glucocorticosteroids is appropriate for symptomatic patients with COPD with an $\mathrm{FEV}_{1}<50 \%$ predicted (stages III and IV) and repeated exacerbations (e.g., three in the last $3 \mathrm{yr})(123-126)$ (Evidence A). This treatment has been shown to reduce the frequency of exacerbations and thus improve health status (127) (Evidence A), and withdrawal from treatment with inhaled glucocorticosteroids can lead to exacerbations in some patients (128). Reanalysis of pooled data from several longer studies of inhaled glucocorticosteroids in COPD suggests that this treatment reduces all-cause mortality (129), but this conclusion requires confirmation in prospective studies before leading to a change in current treatment

TABLE 7. BRONCHODILATORS IN STABLE CHRONIC OBSTRUCTIVE PULMONARY DISEASE

- Bronchodilator medications are central to symptom management in COPD.

- Inhaled therapy is preferred.

- The choice among $\beta_{2}$-agonist, anticholinergic, theophylline, or combination therapy depends on availability and individual response in terms of symptom relief and side effects.

- Bronchodilators are prescribed on an as-needed or on a regular basis to prevent or reduce symptoms.

- Long-acting inhaled bronchodilators are more effective and convenient.

- Combining bronchodilators may improve efficacy and decrease the risk of side effects compared to increasing the dose of a single bronchodilator.

Definition of abbreviation: COPD = chronic obstructive pulmonary disease 
recommendations. An inhaled glucocorticosteroid combined with a long-acting $\beta_{2}$-agonist is more effective than the individual components $(123,125,126,130,131)$ (Evidence A). The doseresponse relationships and long-term safety of inhaled glucocorticosteroids in COPD are not known.

Long-term treatment with oral glucocorticosteroids is not recommended in COPD (Evidence A). A side effect of longterm treatment with systemic glucocorticosteroids is steroid myopathy (132-134), which contributes to muscle weakness, decreased functionality, and respiratory failure in subjects with advanced COPD.

Other Pharmacologic treatments. Vaccines. Influenza vaccines can reduce serious illness (135) and death in patients with COPD by approximately 50\% $(136,137)$ (Evidence A). Vaccines containing killed or live, inactivated viruses are recommended (138) because they are more effective in elderly patients with COPD (139). The strains are adjusted each year for appropriate effectiveness and should be given once each year (140). Pneumococcal polysaccharide vaccine is recommended for patients with COPD who are 65 years and older (141, 142). In addition, this vaccine has been shown to reduce the incidence of community-acquired pneumonia in patients with COPD who are younger than 65 years with an $\mathrm{FEV}_{1}<40 \%$ predicted (143) (Evidence B).

$\alpha_{1}$-Antitrypsin augmentation therapy. Young patients with severe hereditary $\alpha_{1}$-antitrypsin deficiency and established emphysema may be candidates for $\alpha_{1}$-antitrypsin augmentation therapy. However, this therapy is very expensive, not available in most countries, and not recommended for patients with COPD that is unrelated to $\alpha_{1}$-antitrypsin deficiency (Evidence C).

Antibiotics. Prophylactic, continuous use of antibiotics has been shown to have no effect on the frequency of exacerbations in COPD (144-146), and a study that examined the efficacy of chemoprophylaxis undertaken in the winter months over a period of 5 years concluded that there was no benefit (147). There is no current evidence that the use of antibiotics, other than for treating infectious exacerbations of COPD and other bacterial infections, is helpful $(148,149)$ (Evidence A).

Mucolytic (mucokinetic, mucoregulator) agents (ambroxol, erdosteine, carbocysteine, iodinated glycerol). The regular use of mucolytics in COPD has been evaluated in a number of longterm studies with controversial results (150-152). Although a few patients with viscous sputum may benefit from mucolytics $(153,154)$, the overall benefits seem to be very small, and the widespread use of these agents cannot be recommended at present (Evidence D).

Antioxidant agents. Antioxidants, in particular N-acetylcysteine, have been reported in small studies to reduce the frequency of exacerbations, leading to speculation that these medications could have a role in the treatment of patients with recurrent exacerbations (155-158) (Evidence B). However, a large randomized controlled trial found no effect of $\mathrm{N}$ acetylcysteine on the frequency of exacerbations, except in patients not treated with inhaled glucocorticosteroids (159).

Immunoregulators (immunostimulators, immunomodulators). Studies using an immunoregulator in COPD show a decrease in the severity and frequency of exacerbations $(160,161)$. However, additional studies to examine the long-term effects of this therapy are required before its regular use can be recommended (162).

Antitussives. Cough, although sometimes a troublesome symptom in COPD, has a significant protective role (163). Thus, the regular use of antitussives is not recommended in stable COPD (Evidence D).

Vasodilators. In patients with COPD, inhaled nitric oxide can worsen gas exchange because of altered hypoxic regulation of ventilation-perfusion balance $(164,165)$. Therefore, based on the available evidence, nitric oxide is not indicated in stable COPD.

Narcotics (morphine). Oral and parenteral opioids are effective for treating dyspnea in patients with advanced COPD disease. There are insufficient data to conclude whether nebulized opioids are effective (166). However, some clinical studies suggest that morphine used to control dyspnea may have serious adverse effects and its benefits may be limited to a few sensitive subjects (167-171).

Others. Nedocromil, leukotriene modifiers, and alternative healing methods (e.g., herbal medicine, acupunture, homeopathy) have not been adequately tested in patients with COPD and thus cannot be recommended at this time.

Nonpharmacologic treatments. REHABILITATION. The principal goals of pulmonary rehabilitation are to reduce symptoms, improve quality of life, and increase physical and emotional participation in everyday activities. To accomplish these goals, pulmonary rehabilitation covers a range of nonpulmonary problems that may not be adequately addressed by medical therapy for COPD. Such problems, which especially affect patients with stages II through IV COPD, include exercise deconditioning, relative social isolation, altered mood states (especially depression), muscle wasting, and weight loss.

Although more information is needed on criteria for patient selection for pulmonary rehabilitation programs, patients with COPD at all stages of disease appear to benefit from exercise training programs, improving with respect to both exercise tolerance and symptoms of dyspnea and fatigue (172) (Evidence A). Data suggest that these benefits can be sustained even after a single pulmonary rehabilitation program (173-175). Benefit does wane after a rehabilitation program ends, but if exercise training is maintained at home, the patient's health status remains above pre-rehabilitation levels (Evidence B). To date, there is no consensus on whether repeated rehabilitation courses enable patients to sustain the benefits gained through the initial course. Benefits have been reported from rehabilitation programs conducted in inpatient, outpatient, and home settings (176-178).

Ideally, pulmonary rehabilitation should involve several types of health professionals. The components of pulmonary rehabilitation vary widely from program to program, but a comprehensive pulmonary rehabilitation program includes exercise training, nutrition counseling, and education. Baseline and outcome assessments of each participant in a pulmonary rehabilitation program should be made to quantify individual gains and target areas for improvement. Assessments should include the following:

- Detailed history and physical examination

- Measurement of spirometry before and after use of a bronchodilator drug

- Assessment of exercise capacity

- Measurement of health status and impact of breathlessness

- Assessment of inspiratory and expiratory muscle strength and lower limb strength (e.g., quadriceps) in patients who suffer from muscle wasting

The first two assessments are important for establishing entry suitability and baseline status but are not used in outcome assessment. The last three assessments are baseline and outcome measures.

OXYGEN THERAPY The long-term administration of oxygen $(>15 \mathrm{~h} / \mathrm{d})$ to patients with chronic respiratory failure has been shown to increase survival $(179,180)$. It can also have a beneficial impact on hemodynamics, hematologic characteristics, exercise capacity, lung mechanics, and mental state (181). 
Long-term oxygen therapy is generally introduced in patients with stage IV COPD, who have

- $\mathrm{Pa}_{\mathrm{O}_{2}}$ at or below $7.3 \mathrm{kPa}(55 \mathrm{~mm} \mathrm{Hg})$ or $\mathrm{Sa}_{\mathrm{O}_{2}}$ at or below $88 \%$, with or without hypercapnia (Evidence B), or

- $\mathrm{Pa}_{\mathrm{O}_{2}}$ between $7.3 \mathrm{kPa}(55 \mathrm{~mm} \mathrm{Hg})$ and $8.0 \mathrm{kPa}(60 \mathrm{~mm} \mathrm{Hg})$, or $\mathrm{Sa}_{\mathrm{O}_{2}}$ of $88 \%$, if there is evidence of pulmonary hypertension, peripheral edema suggesting congestive cardiac failure, or polycythemia (hematocrit $>55 \%$ ) (Evidence D).

The primary goal of oxygen therapy is to increase the baseline $\mathrm{Pa}_{\mathrm{O}_{2}}$ to at least $8.0 \mathrm{kPa}(60 \mathrm{~mm} \mathrm{Hg})$ at sea level and rest, and/or produce an $\mathrm{Sa}_{\mathrm{O}_{2}}$ of at least $90 \%$, which will preserve vital organ function by ensuring adequate delivery of oxygen. A decision about the use of long-term oxygen should be based on the waking $\mathrm{Pa}_{\mathrm{O}_{2}}$ values. The prescription should always include the source of supplemental oxygen (gas or liquid), method of delivery, duration of use, and flow rate at rest, during exercise, and during sleep.

Ventilatory support. Although long-term noninvasive positive-pressure ventilation (NIPPV) cannot be recommended for the routine treatment of patients with chronic respiratory failure due to COPD, the combination of NIPPV with long-term oxygen therapy may be of some use in a selected subset of patients, particularly in those with pronounced daytime hypercapnia (182).

Surgical treatments. Bullectomy. In carefully selected patients, this procedure is effective in reducing dyspnea and improving lung function (183) (Evidence C). A thoracic CT scan, arterial blood gas measurement, and comprehensive respiratory function tests are essential before making a decision regarding suitability for resection of a bulla.

Lung volume reduction surgery. A large multicenter study of 1,200 patients comparing lung volume reduction surgery with medical treatment has shown that after 4.3 years, patients with upper lobe emphysema and low exercise capacity who received the surgery had a greater survival rate than similar patients who received medical therapy (54 vs. 39.7\%) (184). In addition, the surgery patients experienced greater improvements in their maximal work capacity and their health-related quality of life. The advantage of surgery over medical therapy was less significant among patients who had other emphysema distribution or high exercise capacity before treatment. Although the results of this study showed some very positive results of surgery in a select group of patients $(69,184)$, lung volume reduction surgery is an expensive palliative surgical procedure and can be recommended only in carefully selected patients.

Lung transplantation. In appropriately selected patients with very advanced COPD, lung transplantation has been shown to improve quality of life and functional capacity (185-188) (Evidence C). Criteria for referral for lung transplantation include $\mathrm{FEV}_{1}<35 \%$ predicted, $\mathrm{Pa}_{\mathrm{O}_{2}}<7.3-8.0 \mathrm{kPa}(55-60$ $\mathrm{mm} \mathrm{Hg}), \mathrm{Pa}_{\mathrm{CO}_{2}}>6.7 \mathrm{kPa}(50 \mathrm{~mm} \mathrm{Hg})$, and secondary pulmonary hypertension $(189,190)$.

Special considerations. Surgery IN COPD. Postoperative pulmonary complications are as important and common as postoperative cardiac complications and, consequently, are a key component of the increased risk posed by surgery in patients with COPD. The principal potential factors contributing to the risk include smoking, poor general health status, age, obesity, and COPD severity. A comprehensive definition of postoperative pulmonary complications should include only major pulmonary respiratory complications, namely lung infections, atelectasis, and/or increased airflow obstruction, all potentially resulting in acute respiratory failure and aggravation of underlying COPD (191-196).

\section{Component 4: Manage Exacerbations}

\section{KEY POINTS}

- An exacerbation of COPD is defined as an event in the natural course of the disease characterized by a change in the patient's baseline dyspnea, cough, and/or sputum that is beyond normal day-to-day variations, is acute in onset, and may warrant a change in regular medication in a patient with underlying COPD.

- The most common causes of an exacerbation are infection of the tracheobronchial tree and air pollution, but the cause of about one-third of severe exacerbations cannot be identified (Evidence B).

- Inhaled bronchodilators (particularly inhaled $\beta_{2}$-agonists with or without anticholinergics) and oral glucocorticosteroids are effective treatments for exacerbations of COPD (Evidence A).

- Patients experiencing COPD exacerbations with clinical signs of airway infection (e.g., increased sputum purulence) may benefit from antibiotic treatment (Evidence B).

- Noninvasive mechanical ventilation in exacerbations improves respiratory acidosis, increases $\mathrm{pH}$, decreases the need for endotracheal intubation, and reduces $\mathrm{Pa}_{\mathrm{CO}_{2}}$, respiratory rate, severity of breathlessness, the length of hospital stay, and mortality (Evidence A).

- Medications and education to help prevent future exacerbations should be considered as part of follow-up, because exacerbations affect the quality of life and prognosis of patients with COPD.

Introduction. COPD is often associated with exacerbations of symptoms (197-201). An exacerbation of COPD is defined as "an event in the natural course of the disease characterized by a change in the patient's baseline dyspnea, cough, and/or sputum that is beyond normal day-to-day variations, is acute in onset, and may warrant a change in regular medication in a patient with underlying COPD" $(202,203)$. Exacerbations are categorized in terms of either clinical presentation (number of symptoms [199]) and/or heath care resources utilization (202). The impact of exacerbations is significant and a patient's symptoms and lung function may both take several weeks to recover to the baseline values (204).

The most common causes of an exacerbation are infection of the tracheobronchial tree and air pollution (205), but the cause of approximately one-third of severe exacerbations cannot be identified. The role of bacterial infections is controversial, but recent investigations have shown that at least $50 \%$ of patients have bacteria in high concentrations in their lower airways during exacerbations (206-208). Development of specific immune responses to the infecting bacterial strains, and the association of neutrophilic inflammation with bacterial exacerbations, also support the bacterial causation of a proportion of exacerbations (209-212).

Diagnosis and assessment of severity. MEDICAL HISTORY. Increased breathlessness, the main symptom of an exacerbation, is often accompanied by wheezing and chest tightness, increased cough and sputum, change of the color and/or tenacity of sputum, and fever. Exacerbations may also be accompanied by a number of nonspecific complaints, such as tachycardia and tachypnea, malaise, insomnia, sleepiness, fatigue, depression, 
and confusion. A decrease in exercise tolerance, fever, and/or new radiologic anomalies suggestive of pulmonary disease may herald a COPD exacerbation. An increase in sputum volume and purulence points to a bacterial cause, as does prior history of chronic sputum production $(199,212)$.

AsSESSMENT OF SEVERITY. Assessment of the severity of an exacerbation is based on the patient's medical history before the exacerbation, preexisting comorbidities, symptoms, physical examination, arterial blood gas measurements, and other laboratory tests. Physicians should obtain the results of previous evaluations, where possible, to compare with the current clinical data. Specific information is required on the frequency and severity of attacks of breathlessness and cough, sputum volume and color, and limitation of daily activities. When available, prior arterial blood gas measurements are extremely useful for comparison with those made during the acute episode, as an acute change in these tests is more important than their absolute values. Thus, where possible, physicians should instruct their patients to bring the summary of their last evaluation when they come to the hospital with an exacerbation. In patients with stage IV COPD, the most important sign of a severe exacerbation is a change in the mental status of the patient and this signals a need for immediate evaluation in the hospital.

Spirometry and PEF. Even simple spirometric tests can be difficult for a sick patient to perform properly. These measurements are not accurate during an acute exacerbation; therefore, their routine use is not recommended.

Pulse oximetry and arterial blood gas measurement. Pulse oximetry can be used to evaluate a patient's oxygen saturation and need for supplemental oxygen therapy. For patients that require hospitalization, measurement of arterial blood gases is

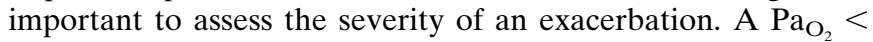
$8.0 \mathrm{kPa}(60 \mathrm{~mm} \mathrm{Hg})$ and/or $\mathrm{Sa}_{\mathrm{O}_{2}}<90 \%$ with or without $\mathrm{Pa}_{\mathrm{CO}_{2}}$ $>6.7 \mathrm{kPa}(50 \mathrm{~mm} \mathrm{Hg})$ when breathing room air indicate respiratory failure. In addition, moderate to severe acidosis $(\mathrm{pH}<7.36)$ plus hypercapnia $\left(\mathrm{Pa}_{\mathrm{CO}_{2}}>6-8 \mathrm{kPa}, 45-60 \mathrm{~mm} \mathrm{Hg}\right)$ in a patient with respiratory failure is an indication for mechanical ventilation $(196,213)$.

Chest $X$-ray and ECG. Chest radiographs (posterior/anterior plus lateral) are useful in identifying alternative diagnoses that can mimic the symptoms of an exacerbation. An ECG aids in the diagnosis of right heart hypertrophy, arrhythmias, and ischemic episodes. Pulmonary embolism can be very difficult to distinguish from an exacerbation, especially in advanced COPD, because right ventricular hypertrophy and large pulmonary arteries lead to confusing ECG and radiographic results. A low systolic blood pressure and an inability to increase the $\mathrm{Pa}_{\mathrm{O}_{2}}$ above $8.0 \mathrm{kPa}(60 \mathrm{~mm} \mathrm{Hg})$ despite high-flow oxygen also suggest pulmonary embolism. If there are strong indications that pulmonary embolism has occurred, it is best to treat for this together with the exacerbation.

Other laboratory tests. The complete blood count may identify polycythemia (hematocrit $>55 \%$ ) or suggest bleeding. White blood cell counts are usually not very informative. The presence of purulent sputum during an exacerbation of symptoms is sufficient indication for starting empirical antibiotic treatment (33). Streptococcus pneumoniae, Hemophilus influenzae, and Moraxella catarrhalis are the most common bacterial pathogens involved in COPD exacerbations. If an infectious exacerbation does not respond to the initial antibiotic treatment, a sputum culture and an antibiogram should be performed.

Biochemical test abnormalities can be associated with an exacerbation and include electrolyte disturbance(s) (e.g., hyponatremia, hypokalemia), poor glucose control, or metabolic acid-base disorder. These abnormalities can also be due to associated comorbid conditions.
Differential diagnoses. Patients with apparent exacerbations of COPD who do not respond to treatment $(204,214)$ should be reevaluated for other medical conditions that can aggravate symptoms or mimic COPD exacerbations (153), including pneumonia, congestive heart failure, pneumothorax, pleural effusion, pulmonary embolism, and cardiac arrhythmia. Noncompliance with the prescribed medication regimen can also cause increased symptoms that may be confused with a true exacerbation. Elevated serum levels of brain-type natriuretic peptide, in conjunction with other clinical information, can identify patients with acute dyspnea secondary to congestive heart failure and enable them to be distinguished from patients with COPD exacerbations $(215,216)$.

Home management. There is increasing interest in home care for patients with end-stage COPD, although the exact criteria for this approach as opposed to hospital treatment remain uncertain and will vary by health care setting (217-220).

BRONCHODILATOR THERAPY. Home management of COPD exacerbations involves increasing the dose and/or frequency of existing short-acting bronchodilator therapy, preferably with a $\beta_{2}$-agonist (Evidence $A$ ). If not already used, an anticholinergic can be added until the symptoms improve (Evidence D).

Glucocorticosteroids. Systemic glucocorticosteroids are beneficial in the management of exacerbations of COPD. They shorten recovery time, improve lung function $\left(\mathrm{FEV}_{1}\right)$ and hypoxemia $\left(\mathrm{Pa}_{\mathrm{O}_{2}}\right)$ (221-224) (Evidence $\mathrm{A}$ ), and may reduce the risk of early relapse, treatment failure, and length of hospital stay (225). They should be considered in addition to bronchodilators if the patient's baseline $\mathrm{FEV}_{1}$ is less than $50 \%$ predicted. A dose of 30 to $40 \mathrm{mg}$ prednisolone per day for 7 to 10 days is recommended $(221,222,226)$.

AntiBiotics. The use of antibiotics in the management of COPD exacerbations is discussed below in HospitAL MANAGEMENT.

Hospital management. The risk of dying of an exacerbation of COPD is closely related to the development of respiratory acidosis, the presence of significant comorbidities, and the need for ventilatory support (227). Patients lacking these features are not at high risk of dying, but those with severe underlying COPD often require hospitalization in any case. Attempts at managing such patients entirely in the community have met with only limited success (228), but returning them to their homes with increased social support and a supervised medical care package after initial emergency room assessment has been much more successful (229). Savings on inpatient expenditures (230) offset the additional costs of maintaining a communitybased COPD nursing team. However, detailed cost-benefit analyses of these approaches are awaited.

A range of criteria to consider for hospital assessment/ admission for exacerbations of COPD are shown in Table 8. Some patients need immediate admission to an intensive care unit (ICU) (Table 9). Admission of patients with severe COPD exacerbations to intermediate or special respiratory care units may be appropriate if personnel, skills, and equipment exist to identify and manage acute respiratory failure successfully.

The first actions when a patient reaches the emergency department are to provide supplemental oxygen therapy and to determine whether the exacerbation is life threatening. If so, the patient should be admitted to the ICU immediately. Otherwise, the patient may be managed in the emergency department or hospital (Table 10).

Controlled oxygen therapy. Oxygen therapy is the cornerstone of hospital treatment of COPD exacerbations. Supplemental oxygen should be titrated to improve the patient's hypoxemia. Adequate levels of oxygenation $\left(\mathrm{Pa}_{\mathrm{O}_{2}}>8.0 \mathrm{kPa}, 60\right.$ $\mathrm{mm} \mathrm{Hg}$, or $\mathrm{Sa}_{\mathrm{O}_{2}}>90 \%$ ) are easy to achieve in uncomplicated 
TABLE 8. INDICATIONS FOR HOSPITAL ASSESSMENT OR ADMISSION FOR EXACERBATIONS OF CHRONIC

\section{OBSTRUCTIVE PULMONARY DISEASE*}

- Marked increase in intensity of symptoms, such as sudden development of resting dyspnea, change in vital signs

- Severe underlying COPD

- Onset of new physical signs (e.g., cyanosis, peripheral edema)

- Failure of exacerbation to respond to initial medical management

- Significant comorbidities

- Frequent exacerbations

- Newly occurring arrhythmias

- Diagnostic uncertainty

- Older age

- Insufficient home support

Definition of abbreviation: COPD = chronic obstructive pulmonary disease

* Local resources need to be considered.

exacerbations, but $\mathrm{CO}_{2}$ retention can occur insidiously with little change in symptoms. Once oxygen is started, arterial blood gases should be checked 30 to 60 minutes later to ensure satisfactory oxygenation without $\mathrm{CO}_{2}$ retention or acidosis. Venturi masks (high-flow devices) offer more accurate delivery of controlled oxygen than do nasal prongs but are less likely to be tolerated by the patient (196).

BRONCHODILATOR THERAPY. Short-acting inhaled $\beta_{2}$-agonists are usually the preferred bronchodilators for treatment of exacerbations of COPD $(153,196,231)$ (Evidence A). If a prompt response to these drugs does not occur, the addition of an anticholinergic is recommended, even though evidence concerning the effectiveness of this combination is controversial. Despite its widespread clinical use, the role of methylxanthines in the treatment of exacerbations of COPD remains controversial. Intravenous methylxanthines (theophylline or aminohylline) are currently considered second-line therapy, used when there is inadequate or insufficient response to short-acting bronchodilators (232-236) (Evidence B). Possible beneficial effects in terms of lung function and clinical endpoints are modest and inconsistent, whereas adverse effects are significantly increased $(237,238)$. There are no clinical studies that have evaluated the use of inhaled long-acting bronchodilators (either $\beta_{2}$-agonists or anticholinergics) with or without inhaled glucocorticosteroids during an acute exacerbation.

Glucocorticosteroids. Oral or intravenous glucocorticosteroids are recommended as an addition to other therapies in the hospital management of exacerbations of COPD $(222,223)$ (Evidence A). The exact dose that should be recommended is not known, but high doses are associated with a significant risk of side effects. Thirty to $40 \mathrm{mg}$ of oral prednisolone daily for 7 to 10 days is effective and safe (Evidence C). Prolonged treatment does not result in greater efficacy and increases the risk of side effects.

\section{TABLE 9. INDICATIONS FOR INTENSIVE CARE UNIT ADMISSION OF PATIENTS WITH EXACERBATIONS OF CHRONIC OBSTRUCTIVE PULMONARY DISEASE*}

- Severe dyspnea that responds inadequately to initial emergency therapy

- Changes in mental status (confusion, lethargy, coma)

- Persistent or worsening hypoxemia $\left(\mathrm{Pa}_{\mathrm{O}_{2}}<5.3 \mathrm{kPa}, 40 \mathrm{~mm} \mathrm{Hg}\right)$, and/or severe/worsening hypercapnia $\left(\mathrm{Pa}_{\mathrm{CO}_{2}}>8.0 \mathrm{kPa}, 60 \mathrm{~mm} \mathrm{Hg}\right)$, and/or severe/worsening respiratory acidosis $(\mathrm{pH}<7.25)$ despite supplemental oxygen and noninvasive ventilation

- Need for invasive mechanical ventilation

- Hemodynamic instability—need for vasopressors

* Local resources need to be considered.
TABLE 10. MANAGEMENT OF SEVERE BUT NOT

LIFE-THREATENING EXACERBATIONS OF CHRONIC OBSTRUCTIVE PULMONARY DISEASE IN THE EMERGENCY DEPARTMENT OR THE HOSPITAL*

- Assess severity of symptoms, blood gases, chest X-ray

- Administer controlled oxygen therapy and repeat arterial blood gas measurement after 30-60 min

- Bronchodilators:

- Increase doses and/or frequency

- Combine $\beta_{2}$-agonists and anticholinergics

- Use spacers or air-driven nebulizers

- Consider adding intravenous methylxanthines, if needed

- Add oral or intravenous glucocorticosteroids

- Consider antibiotics (oral or occasionally intravenous) when there are signs of bacterial infection

- Consider noninvasive mechanical ventilation

- At all times:

- Monitor fluid balance and nutrition

- Consider subcutaneous heparin

- Identify and treat associated conditions (e.g., heart failure, arrhythmias)

- Closely monitor condition of the patient

Data from Reference 226.

* Local resources need to be considered.

Antiвiotics. On the basis of the current available evidence (196, 62), antibiotics should be given to the following individuals:

- Patients with exacerbations of COPD with the following three cardinal symptoms: increased dyspnea, increased sputum volume, and increased sputum purulence (Evidence B)

- Patients with exacerbations of COPD with two of the cardinal symptoms, if increased purulence of sputum is one of the two symptoms (Evidence C)

- Patients with a severe exacerbation of COPD that requires mechanical ventilation (invasive or noninvasive) (Evidence B)

The infectious agents in COPD exacerbations can be viral or bacterial $(140,239)$. The predominant bacteria recovered from the lower airways of patients with COPD exacerbations are $H$. influenzae, S. pneumoniae, and M. catarrhalis (140, 206, 207, 240). So-called atypical pathogens, such as Mycoplasma pneumoniae and Chlamydia pneumoniae $(240,241)$, have been identified in patients with COPD exacerbations, but because of diagnostic limitations the true prevalence of these organisms is not known.

RESPIRATORY sTIMULANTS. Respiratory stimulants are not recommended for acute respiratory failure (231). Doxapram, a nonspecific but relatively safe respiratory stimulant available in some countries as an intravenous formulation, should be used only when noninvasive intermittent ventilation is not available or not recommended (242).

Ventilatory supPORT. The primary objectives of mechanical ventilatory support in patients with COPD exacerbations are to decrease mortality and morbidity and to relieve symptoms. Ventilatory support includes both noninvasive intermittent ventilation using either negative- or positive-pressure devices, and invasive (conventional) mechanical ventilation by orotracheal tube or tracheostomy.

Noninvasive mechanical ventilation. Noninvasive intermittent ventilation (NIV) has been studied in several randomized controlled trials in acute respiratory failure, consistently providing positive results, with success rates of 80 to $85 \%$ (182, 243-245). These studies provide evidence that NIV improves respiratory acidosis (increases $\mathrm{pH}$, and decreases $\mathrm{Pa}_{\mathrm{CO}_{2}}$ ), and decreases respiratory rate, severity of breathlessness, and length of hospital stay (Evidence A). More importantly, mortality —or 
its surrogate, intubation rate-is reduced by this intervention (245-248). However, NIV is not appropriate for all patients, as summarized in Table 11 (182).

Invasive mechanical ventilation. The indications for initiating invasive mechanical ventilation during exacerbations of COPD are shown in Table 12 and include failure of an initial trial of NIV (252). As experience is being gained with the generalized clinical use of NIV in COPD, several of the indications for invasive mechanical ventilation are being successfully treated with NIV.

The use of invasive ventilation in patients with end-stage COPD is influenced by the likely reversibility of the precipitating event, the patient's wishes, and the availability of intensive care facilities. Major hazards include the risk of ventilatoracquired pneumonia (especially when multiresistant organisms are prevalent), barotrauma, and failure to wean to spontaneous ventilation. Contrary to some opinions, acute mortality among patients with COPD with respiratory failure is lower than mortality among patients ventilated for non-COPD causes (253). When possible, a clear statement of the patient's own treatment wishes - an advance directive or "living will"-makes these difficult decisions much easier to resolve.

Weaning or discontinuation from mechanical ventilation can be particularly difficult and hazardous in patients with COPD and the best method (pressure support or a T-piece trial) remains a matter of debate (254-256). In patients with COPD who fail weaning trials, noninvasive ventilation facilitates extubation. It can also prevent reintubation in patients with extubation failure and may reduce mortality.

OTHER MEASURES. Further treatments that can be used in the hospital include the following: fluid administration (accurate monitoring of fluid balance is essential); nutrition (supplementary when needed); deep venous thrombosis prophylaxis (mechanical devices, heparins, etc.) in immobilized, polycythemic, or dehydrated patients with or without a history of thromboembolic disease; and sputum clearance (by stimulating coughing and low-volume forced expirations as in home management). Manual or mechanical chest percussion and postural drainage may be beneficial in patients with excessive sputum production or with lobar atelectasis.

Hospital discharge and follow-up. Insufficient clinical data exist to establish the optimal duration of hospitalization in individual patients who develop an exacerbation of COPD (197, 257, 258). Consensus and limited data support the discharge

TABLE 11. INDICATIONS AND RELATIVE CONTRAINDICATIONS FOR NONINVASIVE INTERMITTENT VENTILATION

Selection criteria

- Moderate to severe dyspnea with use of accessory muscles and paradoxical abdominal motion

- Moderate to severe acidosis $(\mathrm{pH} \leqslant 7.35)$ and/or hypercapnia $\left(\mathrm{Pa}_{\mathrm{CO}_{2}}>6.0 \mathrm{kPa}, 45 \mathrm{~mm} \mathrm{Hg}\right)(251)$

- Respiratory frequency $>25$ breaths/min

Exclusion criteria (any may be present)

- Respiratory arrest

- Cardiovascular instability (hypotension, arrhythmias, myocardial infarction)

- Change in mental status; uncooperative patient

- High aspiration risk

- Viscous or copious secretions

- Recent facial or gastroesophageal surgery

- Craniofacial trauma

- Fixed nasopharyngeal abnormalities

- Burns

- Extreme obesity

Data from References 196, 243, 249, and 250.
TABLE 12. INDICATIONS FOR INVASIVE MECHANICAL VENTILATION

- Unable to tolerate NIV or NIV failure (or exclusion criteria, see Table 11)

- Severe dyspnea with use of accessory muscles and paradoxical abdominal motion

- Respiratory frequency $>35$ breaths/min

- Life-threatening hypoxemia

- Severe acidosis ( $\mathrm{pH}<7.25)$ and/or hypercapnia $\left(\mathrm{Pa}_{\mathrm{CO}_{2}}>8.0 \mathrm{kPa}, 60 \mathrm{~mm} \mathrm{Hg}\right)$

- Respiratory arrest

- Worsening in mental status despite optimal therapy

- Cardiovascular complications (hypotension, shock)

- Other complications (metabolic abnormalities, sepsis, pneumonia, pulmonary embolism, barotrauma, massive pleural effusion)

Definition of abbreviation: NIV = noninvasive intermittent ventilation.

criteria listed in Table 13. Table 14 provides items to include in a follow-up assessment 4 to 6 weeks after discharge from the hospital. Thereafter, follow-up is the same as for patients with stable COPD, including supervising smoking cessation, monitoring the effectiveness of each drug treatment, and monitoring changes in spirometric parameters (229). Home visits by a community nurse may permit earlier discharge of patients hospitalized with an exacerbation of COPD, without increasing readmission rates $(153,259-261)$.

In patients who are hypoxemic during a COPD exacerbation, arterial blood gases and/or pulse oximetry should be evaluated before hospital discharge and in the following 3 months. If the patient remains hypoxemic, long-term supplemental oxygen therapy may be required.

Opportunities for prevention of future exacerbations should be reviewed before discharge, with particular attention to smoking cessation, current vaccination (influenza, pneumococcal vaccines), knowledge of current therapy including inhaler technique $(32,262,263)$, and how to recognize symptoms of exacerbations. Pharmacotherapy known to reduce the number of exacerbations and hospitalizations and delay the time of first/ next hospitalization, such as long-acting inhaled bronchodilators, inhaled glucocorticosteroids, and combination inhalers, should be specifically considered. Social problems should be discussed and principal caregivers identified if the patient has a significant persisting disability.

\section{TRANSLATING GUIDELINE RECOMMENDATIONS TO THE CONTEXT OF (PRIMARY) CARE}

\section{KEY POINTS}

- There is considerable evidence that management of COPD is generally not in accordance with current guidelines. Better dissemination of guidelines and their effective implementation in a variety of health care settings are urgently required.

- In many countries, primary care practitioners treat the vast majority of patients with COPD and may be actively involved in public health campaigns and in bringing messages about reducing exposure to risk factors to both patients and the public.

- Spirometric confirmation is a key component of the diagnosis of COPD and primary care practitioners should have access to high-quality spirometry.

- Older patients frequently have multiple chronic health conditions. Comorbidities can magnify the impact of COPD on a patient's health status, and can complicate the management of COPD. 
TABLE 13. DISCHARGE CRITERIA FOR PATIENTS WITH EXACERBATIONS OF CHRONIC OBSTRUCTIVE PULMONARY DISEASE

- Inhaled $\beta_{2}$-agonist therapy is required no more frequently than every $4 \mathrm{~h}$

- Patient, if previously ambulatory, is able to walk across room

- Patient is able to eat and sleep without frequent awakening by dyspnea

- Patient has been clinically stable for 12-24 h

- Arterial blood gases have been stable for 12-24 h

- Patient (or home caregiver) fully understands correct use of medications

- Follow-up and home care arrangements have been completed (e.g., visiting nurse, oxygen delivery, meal provisions)

- Patient, family, and physician are confident patient can manage successfully at home

The recommendations provided in sections 1 through 3 define-from a disease perspective-best practices in the diagnosis, monitoring, and treatment of COPD. However, (primary) medical care is based on an engagement with patients, and this engagement determines the success or failure of pursuing best practice. For this reason, medical practice requires a translation of disease-specific recommendations to the circumstances of individual patients-with regard to the local communities in which they live, and the health systems from which they receive medical care.

\section{Diagnosis}

In pursuing early diagnosis, a policy of identifying patients at high risk of COPD, followed by watchful surveillance of these patients, is advised.

Respiratory symptoms. Of the chronic symptoms characteristic of COPD (dyspnea, cough, sputum production), dyspnea is the symptom that interferes most with a patient's daily life and health status. When taking the medical history of the patient, it is therefore important to explore the impact of dyspnea and other symptoms on daily activities, work, and social activities, and provide treatment accordingly.

Spirometry. High-quality spirometry in primary care is possible $(264,265)$, provided that good skills training and an ongoing quality assurance program are provided. An alternative is to ensure that high-quality spirometry is available in the community-for example, within the primary care practice itself, in a primary care laboratory, or in a hospital setting, depending on the structure of the local health care system (266). Ongoing collaboration between primary care and respiratory care also helps assure quality control.

\section{Comorbidities}

Older patients frequently have multiple chronic health conditions and the severity of comorbid conditions and their impact on a patient's health status will vary between patients and in the same patient over time. Comorbidities for patients with COPD may include the following: other smoking-related diseases, such

TABLE 14. ITEMS TO ASSESS AT FOLLOW-UP VISIT 4-6 WEEKS AFTER DISCHARGE FROM HOSPITAL FOR EXACERBATIONS OF CHRONIC OBSTRUCTIVE PULMONARY DISEASE

- Ability to cope in usual environment

- Measurement of FEV 1

- Reassessment of inhaler technique

- Understanding of recommended treatment regimen

- Need for long-term oxygen therapy and/or home nebulizer (for patients with stage IV, very severe COPD)

Definition of abbreviation: COPD = chronic obstructive pulmonary disease. as ischemic heart disease and lung cancer; conditions that arise as a complication of a specific preexisting disease, such as pulmonary hypertension and consequent heart failure; coexisting chronic conditions with unrelated pathogenesis related to aging, such as bowel or prostate cancer, depression, diabetes mellitus, Parkinson's disease, dementia, and arthritis; or acute illnesses that may have a more severe impact in patients with a given chronic disease. For example, upper respiratory tract infections are the most frequent health problem in all age groups, but they may have a more severe impact or require different treatment in patients with COPD.

\section{Reducing Exposure to Risk Factors}

Reduction of total personal exposure to tobacco smoke, occupational dusts and chemicals, and indoor and outdoor air pollutants, including smoke from cooking over biomass-fueled fires, is an important goal to prevent the onset and progression of COPD. In many health care systems, primary care practitioners may be actively involved in public health campaigns and can play an important part in bringing messages about reducing exposure to risk factors to patients and the public. Primary care practitioners can also play a very important role in reinforcing the dangers of passive smoking and the importance of implementing smoke-free work environments.

Smoking cessation is the most effective intervention to reduce the risk of developing COPD, and simple smoking cessation advice from health care professionals has been shown to make patients more likely to stop smoking. Primary care practitioners often have many contacts with a patient over time, which provides the opportunity to discuss smoking cessation, enhance motivation for quitting, and identify the need for supportive pharmacologic treatment. It is very important to align the advice given by individual practitioners with public health campaigns to send a coherent message to the public.

\section{Implementation of COPD Guidelines}

GOLD national leaders play an essential role in the dissemination of information about prevention, early diagnosis, and management of COPD in health systems around the world. A major GOLD program activity that has helped to bring together health care teams at the local level is World COPD Day, held annually on the third Wednesday in November.* GOLD national leaders, often in concert with local physicians, nurses, and health care planners, have hosted many types of activities to raise awareness of COPD. WONCA (the World Organization of Family Doctors) is also an active collaborator in organizing World COPD Day activities. Increased participation of a wide variety of health care professionals in World COPD Day activities in many countries would help to increase awareness of COPD.

GOLD is a partner organization in the World Health Organization's GARD with the goal to raise awareness of the burden of chronic respiratory diseases in all countries of the world, and to disseminate and implement recommendations from international guidelines.

Although awareness and dissemination of guidelines are important goals, the actual implementation of a comprehensive care system in which to coordinate the management of COPD will be important to pursue. Evidence is increasing that a chronic disease management program for patients with COPD that incorporates a variety of interventions, includes pulmonary rehabilitation, and is implemented by primary care reduces hospital admissions and bed days. Key elements are patient participation and information sharing among health care providers (267).

*For further information on World COPD Day: http://www.goldcopd.org/WCDindex. asp. 
Conflict of Interest Statement: K.F.R. has consulted, participated in advisory board meetings, and received lecture fees from AstraZeneca, Boehringer Ingelheim (BI), Chiesi Pharmaceuticals, Pfizer, Novartis, AltanaPharma, Merck, Sharp, and Dohme (MSD), and GlaxoSmithKline (GSK). The Department of Pulmonology, and thereby K.F.R. as head of the department, has received grants from AltanaPharma $(\$ 222,612)$, Novartis $(\$ 90,640)$, AstraZeneca $(\$ 113,155)$, Pfizer $(\$ 406,000)$, MSD $(\$ 118,000)$, Exhale Therapeutics $(\$ 90,000), \mathrm{BI}(\$ 90,000)$, Roche $(\$ 120,000)$, and GSK $(\$ 299,495)$ in the years 2001 until 2006. S.H. does not have a financial relationship with a commercial entity that has an interest in the subject of this manuscript. A.A. served as consultant in 2006 for Bayer Pharma $(\$ 2,000)$, Sanofi Aventis $(\$ 2,500)$, GSK $(\$ 2,000), \mathrm{BI}(\$ 2,000)$, and Sepracor $(\$ 3,000)$. He received lecture fees from BI/Pfizer for $\$ 3,000$, Bayer Pharma for $\$ 2,500$, and for symposia from BI for $\$ 1,500$ and symposia from Kinetic Concepts, Inc. for $\$ 2,000$. He also received industry-sponsored grants from Bayer Pharma in 2004-2005 for $\$ 30,000$, C.R. Bard, Inc. for $\$ 60,000$, BI for $\$ 50,000$, NHLBI for $\$ 200,000$, and GSK for $\$ 200,000$. P.J.B. has received research funding, lecture fees, and has served on scientific advisory boards for GSK, AstraZeneca, BI, Novartis, AltanaPharma, and Pfizer. S.A.B. has served on advisory boards for GSK, Altana, Schering Plough, Merck, Novartis, Pfizer, and Sepracor. She has participated in COPD workshops funded by AstraZeneca and GSK; and is Scientific Director for the Burden of Obstructive Lung Disease (BOLD) initiative, which receives unrestricted educational grants to the Kaiser Permanente Center for Health Research from GSK, Pfizer, $\mathrm{BI}$, AstraZeneca, AltanaPharma, Novartis, Merck, Chiesi, Schering Plough, and Sepracor. P.C. has spoken at scientific meetings for which he received honoraria (GSK, 2004-2006, \$10,000; AstraZeneca, 2006, \$3,000) and has served on advisory boards (GSK, 2004-2006, \$15,000; AstraZeneca, 2004, \$2,500; Pfizer, 2005-2006, \$5,000). He has received industry-sponsored grants from GSK $(\$ 110,000)$ and AltanaPharma $(\$ 40,000)$. Y.F. does not have a financial relationship with a commercial entity that has an interest in the subject of this manuscript. C.J. has received fees for chairing or sitting on advisory boards of GSK, AstraZeneca, and Pfizer/BI, for a total value of $\$ 22,000$ in the last 3 years. C.J. has also received fees for providing educational material and for giving lectures at industry-sponsored symposia to the value of $\$ 8,500$ in the last 3 years. C.J. is a senior researcher in the Woolcock Institute of Medical Research, which participates in clinical trials sponsored by GSK, AstraZeneca, AltanaPharma (now NycoMed), and BI. The Institute is a member of a national collaborative research group, which is cofunded by government and industry. The major industry partners are GSK and Pharmaxis. R.R.-R. has participated as a lecturer and speaker in scientific meetings and courses under the sponsorship of Almirall, AstraZeneca, BI, GSK, Laboratorios Dr Esteve SA, and Pfizer; consulted with several pharmaceutical companies with interests in the topics discussed in the present article (Almirall, AltanaPharma, AstraZeneca, BI, GSK, Laboratorios Dr. Esteve SA, Novartis, Pfizer, Viechi, and Zambon); serves on advisory boards for Almirall, BI, GSK, Novartis, Pfizer, Proctor and Gamble, and Viechi; has been sponsored for several clinical trials; and has received laboratory research support from AstraZeneca, BI, GSK, Laboratorios Dr Esteve SA, Pfizer, and Proctor and Gamble Ltd. C.v.W. has received speakers fees from Novartis, BI, AltanaPharma, and Pfizer, which have all been made available to the World Organization of Family Doctors (WONES). His department has received unrestricted research grants from GSK, BI, AstraZeneca, Novartis, Novo Nordisk, and Bayer. J.Z. does not have a financial relationship with a commercial entity that has an interest in the subject of this manuscript.

\section{References}

1. National Heart, Lung, and Blood Institute. 2004 NHLBI morbidity and mortality chartbook on cardiovascular, lung and blood diseases [Internet]. Bethesda, MD: U.S. Department of Health and Human Services, Public Health Service, National Institutes of Health [accessed 2007 Jul 26]. Available from: http://www.nhlbi.nih.gov/resources/docs/cht-book.htm

2. Lopez AD, Shibuya K, Rao C, Mathers CD, Hansell AL, Held LS, Schmid V, Buist S. Chronic obstructive pulmonary disease: current burden and future projections. Eur Respir J 2006;27:397-412.

3. Global Initiative for Chronic Obstructive Lung Disease. Global strategy for diagnosis, management, and prevention of COPD [Internet] [updated 2005]. Available from: http://www.goldcopd.org

4. Soriano JB, Visick GT, Muellerova H, Payvandi N, Hansell AL. Patterns of comorbidities in newly diagnosed COPD and asthma in primary care. Chest 2005;128:2099-2107.

5. Agusti AG. Systemic effects of chronic obstructive pulmonary disease. Proc Am Thorac Soc 2005;2:367-370.

6. Johannessen A, Lehmann S, Omenaas ER, Eide GE, Bakke PS, Gulsvik A. Post-bronchodilator spirometry reference values in adults and implications for disease management. Am J Respir Crit Care Med 2006;173:1316-1325.

7. Fairall LR, Zwarenstein M, Bateman ED, Bachmann M, Lombard C, Majara BP, Joubert G, English RG, Bheekie A, van Rensburg D, et al. Effect of educational outreach to nurses on tuberculosis case detection and primary care of respiratory illness: pragmatic cluster randomised controlled trial. BMJ 2005;331:750-754.

8. de Valliere S, Barker RD. Residual lung damage after completion of treatment for multidrug-resistant tuberculosis. Int J Tuberc Lung Dis 2004;8:767-771.
9. Bateman ED, Feldman C, O'Brien J, Plit M, Joubert JR. Guideline for the management of chronic obstructive pulmonary disease (COPD): 2004 revision. S Afr Med J 2004;94:559-575.

10. Hogg JC. Pathophysiology of airflow limitation in chronic obstructive pulmonary disease. Lancet 2004;364:709-721.

11. Birring SS, Brightling CE, Bradding P, Entwisle JJ, Vara DD, Grigg J, et al. Clinical, radiologic, and induced sputum features of chronic obstructive pulmonary disease in nonsmokers: a descriptive study. Am J Respir Crit Care Med 2002;166:1078-1083.

12. Wouters EF, Creutzberg EC, Schols AM. Systemic effects in COPD. Chest 2002;121:127S-130S.

13. Agusti AG, Noguera A, Sauleda J, Sala E, Pons J, Busquets X. Systemic effects of chronic obstructive pulmonary disease. Eur Respir J 2003;21:347-360.

14. Tirimanna PR, van Schayck CP, den Otter JJ, van Weel C, van Herwaarden CL, van den Boom G, van Grunsven PM, van den Bosch WJ. Prevalence of asthma and COPD in general practice in 1992: has it changed since 1977? Br J Gen Pract 1996;46:277-281.

15. Halbert RJ, Natoli JL, Gano A, Badamgarav E, Buist AS, Mannino DM. Global burden of COPD: systematic review and meta-analysis. Eur Respir J 2006;28:523-532.

16. Fukuchi Y, Nishimura M, Ichinose M, Adachi M, Nagai A, Kuriyama T, Takahashi K, Nishimura K, Ishioka S, Aizawa H, et al. COPD in Japan: the Nippon COPD Epidemiology study. Respirology 2004;9: $458-465$.

17. National Heart, Lung, and Blood Institute. Morbidity and mortality: chartbook on cardiovascular, lung, and blood Diseases. Bethesda, MD: U.S. Department. of Health and Human Services, Public Health Service, National Institutes of Health; 1998.

18. Soriano JR, Maier WC, Egger P, Visick G, Thakrar B, Sykes J, Pride NB. Recent trends in physician diagnosed COPD in women and men in the UK. Thorax 2000;55:789-794.

19. Menezes AM, Perez-Padilla R, Jardim JR, Muino A, Lopez MV, Valdivia G, Montes de Oca M, Talamo C, Hallal PC, Victora CG. Chronic obstructive pulmonary disease in five Latin American cities (the PLATINO study): a prevalence study. Lancet 2005;366:18751881.

20. Schellevis FG, Van de Lisdonk EH, Van der Velden J, Hoogbergen SH, Van Eijk JT, Van Weel C. Consultation rates and incidence of intercurrent morbidity among patients with chronic disease in general practice. Br J Gen Pract 1994;44:259-262.

21. Murray CJL, Lopez AD, editors. The global burden of disease: a comprehensive assessment of mortality and disability from diseases, injuries and risk factors in 1990 and projected to 2020. Cambridge, MA: Harvard University Press; 1996.

22. Murray CJ, Lopez AD. Alternative projections of mortality and disability by cause 1990-2020: Global Burden of Disease Study. Lancet 1997;349:1498-1504.

23. European Respiratory Society. European lung white book. Huddersfield, UK: European Respiratory Society Journals; 2003.

24. Chapman KR, Mannino DM, Soriano JB, Vermeire PA, Buist AS, Thun MJ, Connell C, Jemal A, Lee TA, Miravitlles M, et al. Epidemiology and costs of chronic obstructive pulmonary disease. Eur Respir J 2006;27:188-207.

25. Jansson SA, Andersson F, Borg S, Ericsson A, Jonsson E, Lundback B. Costs of COPD in Sweden according to disease severity. Chest 2002;122:1994-2002.

26. Celli BR, Halbert RJ, Nordyke RJ, Schan B. Airway obstruction in never smokers: results from the Third National Health and Nutrition Examination Survey. Am J Med 2005;118:1364-1372.

27. Behrendt CE. Mild and moderate-to-severe COPD in non-smokers: distinct demographic profiles. Chest 2005;128:1239-1244.

28. Stoller JK, Aboussouan LS. Alpha1-antitrypsin deficiency. Lancet 2005;365:2225-2236.

29. Blanco I, de Serres FJ, Fernandez-Bustillo E, Lara B, Miravitlles M. Estimated numbers and prevalence of $\mathrm{PI}{ }^{*} \mathrm{~S}$ and $\mathrm{PI} * \mathrm{Z}$ alleles of alpha1antitrypsin deficiency in European countries. Eur Respir $J$ 2006;27: $77-84$.

30. Silverman EK, Palmer LJ, Mosley JD, Barth M, Senter JM, Brown A, Drazen JM, Kwiatkowski DJ, Chapman HA, Campbell EJ, et al. Genomewide linkage analysis of quantitative spirometric phenotypes in severe early-onset chronic obstructive pulmonary disease. Am J Hum Genet 2002;70:1229-1239.

31. U.S. Surgeon General. The health consequences of smoking: chronic obstructive pulmonary disease. Washington, DC: U.S. Department of Health and Human Services; 1984. 
32. Jindal SK, Aggarwal AN, Chaudhry K, Chhabra SK, D'Souza GA, Gupta D, Katiyar SK, Kumar R, Shah B, Vijayan VK. A multicentric study on epidemiology of chronic obstructive pulmonary disease and its relationship with tobacco smoking and environmental tobacco smoke exposure. Indian J Chest Dis Allied Sci 2006;48:23-29.

33. Al-Fayez SF, Salleh M, Ardawi M. Azahran FM. Effects of sheesha and cigarette smoking on pulmonary function of Saudi males and females. Trop Geogr Med 1988;40:115-123.

34. Smith CA, Harrison DJ. Association between polymorphism in gene for microsomal epoxide hydrolase and susceptibility to emphysema. Lancet 1997;350:630-633.

35. U.S. Surgeon General. The health consequences of involuntary exposure to tobacco smoke. a report of the Surgeon General. Washington, DC: Department of Health and Human Services; 2006.

36. Eisner MD, Balmes J, Katz BP, Trupin L, Yelin E, Blanc P. Lifetime environmental tobacco smoke exposure and the risk of chronic obstructive pulmonary disease. Environ Health Perspect 2005;4:7-15.

37. Leuenberger P, Schwartz J, Ackermann-Liebrich U, Blaser K, Bolognini G, Bongard JP, Brandli O, Braun $\mathrm{P}$, Bron C, Brutsche M, et al. Passive smoking exposure in adults and chronic respiratory symptoms (SAPALDIA). Swiss Study on Air Pollution and Lung Diseases in Adults, SAPALDIA Team. Am J Respir Crit Care Med 1994;150: $1222-1228$.

38. Dayal HH, Khuder S, Sharrar R, Trieff N. Passive smoking in obstructive respiratory disease in an industrialized urban population. Environ Res 1994;65:161-171.

39. Tager IB, Ngo L, Hanrahan JP. Maternal smoking during pregnancy: effects on lung function during the first 18 months of life. Am J Respir Crit Care Med 1995;152:977-983.

40. Holt PG. Immune and inflammatory function in cigarette smokers. Thorax 1987;42:241-249.

41. Balmes J, Becklake M, Blanc P, Henneberger P, Kreiss K, Mapp C, Milton D, Schwartz D, Toren K, Viegi G. American Thoracic Society statement: occupational contribution to the burden of airway disease. Am J Respir Crit Care Med 2003;167:787-797.

42. Warwick H, Doig A. Smoke the killer in the kitchen: indoor air pollution in developing countries. London: ITDG Publishing; 2004.

43. Ezzati M. Indoor air pollution and health in developing countries. Lancet 2005;366:104-106.

44. Smith KR, Mehta S, Maeusezahl-Feuz M. Indoor air-pollution from household solid fuel use. In: Ezzati M., Lopez AD, Rodgers M., Murray CJ, editors. Comparative quantification of health risks: global and regional burden of disease attributable to selected major risk factors. Geneva, Switzerland: World Health Organization; 2004.

45. Mishra V, Dai X, Smith KR, Mika L. Maternal exposure to biomass smoke and reduced birth weight in Zimbabwe. Ann Epidemiol 2004;14:740-747.

46. Boman C, Forsberg B, Sandstrom T. Shedding new light on wood smoke: a risk factor for respiratory health. Eur Respir J 2006;27:446447.

47. Oroczo-Levi M. Garcia-Aymerich J, Villar J, Ramirez-Sarmiento A, Anto JM, Gea J. Wood smoke exposure and risk of chronic obstructive pulmonary disease. Eur Respir J 2006;27:542-546.

48. Sezer H, Akkurt I, Guler N, Marakoglu K, Berk S. A case-control study on the effect of exposure to different substances on the development of COPD. Ann Epidemiol 2006;16:59-62.

49. Mannino DM, Homa DM, Akinbami LJ, Ford ES, Redd SC. Chronic obstructive pulmonary disease surveillance: United States, 1971-2000. MMWR Surveill Summ 2002;51:1-16.

50. Xu X, Weiss ST, Rijcken B, Schouten JP. Smoking, changes in smoking habits, and rate of decline in $\mathrm{FEV}_{1}$ : new insight into gender differences. Eur Respir J 1994;7:1056-1061.

51. Anthonisen NR, Connett JE, Kiley JP, Altose MD, Bailey WC, Buist AS, Conway WA Jr, Enright PL, Kanner RE, O'Hara P, et al. Effects of smoking intervention and the use of an inhaled anticholinergic bronchodilator on the rate of decline of $\mathrm{FEV}_{1}$. The Lung Health Study. JAMA 1994;272:1497-1505.

52. Silverman EK, Weiss ST, Drazen JM, Chapman HA, Carey V, Campbell EJ, Denish P, Silverman RA, Celedon JC, Reilly JJ, et al. Gender-related differences in severe, early-onset chronic obstructive pulmonary disease. Am J Respir Crit Care Med 2000;162:21522158.

53. Tager IB, Segal MR, Speizer FE, Weiss ST. The natural history of forced expiratory volumes: effect of cigarette smoking and respiratory symptoms. Am Rev Respir Dis 1988;138:837-849.
54. Barker DJ, Godfrey KM, Fall C, Osmond C, Winter PD, Shaheen SO. Relation of birth weight and childhood respiratory infection to adult lung function and death from chronic obstructive airways disease. BMJ 1991;303:671-675.

55. Shaheen SO, Barker DJ, Shiell AW, Crocker FJ, Wield GA, Holgate ST. The relationship between pneumonia in early childhood and impaired lung function in late adult life. Am J Respir Crit Care Med 1994:149:616-619.

56. Prescott E, Lange P, Vestbo J. Socioeconomic status, lung function and admission to hospital for COPD: results from the Copenhagen City Heart Study. Eur Respir J 1999;13:1109-1114.

57. Tao X, Hong CJ, Yu S, Chen B, Zhu H, Yang M. Priority among air pollution factors for preventing chronic obstructive pulmonary disease in Shanghai. Sci Total Environ 1992;127:57-67.

58. U.S. Centers for Disease Control and Prevention. Criteria for a recommended standard: occupational exposure to respirable coal mine dust. Atlanta, GA: National Institute of Occupational Safety and Health; 1995.

59. Georgopoulas D, Anthonisen NR. Symptoms and signs of COPD. In: Cherniack NS, editor. Chronic obstructive pulmonary disease. Toronto, ON, Canada: W.B. Saunders; 1991. pp. 357-363.

60. Schols AM, Soeters PB, Dingemans AM, Mostert R, Frantzen PJ, Wouters EF. Prevalence and characteristics of nutritional depletion in patients with stable COPD eligible for pulmonary rehabilitation. Am Rev Respir Dis 1993;147:1151-1156.

61. Calverley PMA. Neuropsychological deficits in chronic obstructive pulmonary disease [editorial]. Monaldi Arch Chest Dis 1996;51:5-6.

62. Holguin F, Folch E, Redd SC, Mannino DM. Comorbidity and mortality in COPD-related hospitalizations in the United States, 1979 to 2001. Chest 2005;128:2005-2011.

63. Kesten S, Chapman KR. Physician perceptions and management of COPD. Chest 1993;104:254-258.

64. Loveridge B, West P, Kryger MH, Anthonisen NR. Alteration in breathing pattern with progression of chronic obstructive pulmonary disease. Am Rev Respir Dis 1986;134:930-934.

65. Pellegrino R, Viegi G, Brusasco V, Crapo RO, Burgos F, Casaburi R, Coates A, van der Grinten CP, Gustafsson P, Hankinson J,et al. Interpretative strategies for lung function tests. Eur Respir J 2005;26: 948-968.

66. Hardie JA, Buist AS, Vollmer WM, Ellingsen I, Bakke PS, Morkve O. Risk of over-diagnosis of COPD in asymptomatic elderly neversmokers. Eur Respir J 2002;20:1117-1122.

67. Burge PS, Calverley PM, Jones PW, Spencer S, Anderson JA. Prednisolone response in patients with chronic obstructive pulmonary disease: results from the ISOLDE study. Thorax 2003;58:654-658.

68. Calverley PM, Burge PS, Spencer S, Anderson JA, Jones PW. Bronchodilator reversibility testing in chronic obstructive pulmonary disease. Thorax 2003;58:659-664.

69. Fishman A, Martinez F, Naunheim K, Piantadosi S, Wise R, Ries A, Weinmann G, Wood DE. A randomized trial comparing lung-volumereduction surgery with medical therapy for severe emphysema. N Engl J Med 2003;348:2059-2073.

70. Wilson DH, Wakefield MA, Steven ID, Rohrsheim RA, Esterman AJ, Graham NM. "Sick of smoking": evaluation of a targeted minimal smoking cessation intervention in general practice. Med J Aust 1990; 152:518-521.

71. Britton J, Knox A. Helping people to stop smoking: the new smoking cessation guidelines. Thorax 1999;54:1-2.

72. Fiore MC, Bailey WC, Cohen SJ, Dorfman SF, Fox BJ, Goldstein MG, Gritz E, Hasselblad V, Heyman RB, Jaen CR, et al:; The Tobacco Use and Dependence Clinical Practice Guideline Panel, Staff, and Consortium Representatives. A clinical practice guideline for treating tobacco use and dependence: A US Public Health Service report. JAMA 2000; 28:3244-3254

73. American Medical Association. Guidelines for the diagnosis and treatment of nicotine dependence: how to help patients stop smoking. Washington, DC: American Medical Association; 1994.

74. Glynn TJ, Manley MW. How to help your patients stop smoking: a National Cancer Institute manual for physicians. Bethesda, MD: U.S. Department of Health and Human Services, Public Health Service, National Institutes of Health, National Cancer Institute; 1990.

75. Glynn TJ, Manley MW, Pechacek TF. Physician-initiated smoking cessation program: the National Cancer Institute trials. Prog Clin Biol Res 1990;339:11-25.

76. Fiore MC, Bailey WC, Cohen SJ. Smoking cessation: information for specialists. Rockville, MD: U.S. Department of Health and Human 
Services, Public Health Service, Agency for Health Care Policy and Research, and Centers for Disease Control and Prevention; 1996.

77. Lancaster T, Stead L, Silagy C, Sowden A. Effectiveness of interventions to help people stop smoking: findings from the Cochrane Library. BMJ 2000;321:355-358.

78. Tashkin D, Kanner R, Bailey W, Buist S, Anderson P, Nides M, Gonzales D, Dozier G, Patel MK, Jamerson B. Smoking cessation in patients with chronic obstructive pulmonary disease: a double-blind, placebo-controlled, randomised trial. Lancet 2001;357:1571-1575.

79. Jorenby DE, Leischow SJ, Nides MA, Rennard SI, Johnston JA, Hughes AR, Smith SS, Muramoto ML, Daughton DM, Doan K, et al. A controlled trial of sustained-release bupropion, a nicotine patch, or both for smoking cessation. N Engl J Med 1999;340:685-691.

80. Jorenby DE, Hays JT, Rigotti NA, Axoulay S, Watsky EJ, Williams KE, Billing CB, Gong J, Reeves KR; Varenicline Phase 3 Study Group. Efficacy of varenicline, an alpha4beta2 nicotinic acetylcholine receptor partial agonist, vs placebo or sustained-release bupropion for smoking cessation: a randomized controlled trial. JAMA 2006;296:5663.

81. Nides M, Oncken C, Gonzales D, Rennard S, Watsky EJ, Anziano R, Reeves KR. Smoking cessation with varenicline, a selective alpha4beta2 nicotinic receptor partial agonist: results from a 7-week, randomized, placebo- and bupropion-controlled trial with 1-year follow-up. Arch Intern Med 2006;166:1561-1568.

82. Tonstad S, Tonnesen P, Hajek P, Williams KE, Billing CB, Reeves KR, Varenicline Phase 3 Study Group. Effect of maintenance therapy with varenicline on smoking cessation: a randomized controlled trial. JAMA 2006;296:64-71.

83. Chapman RS, Xingzhou H, Blair AE, Lan Q. Improvement in household stoves and risk of chronic obstructive pulmonary disease in Xuanwei, China: retrospective cohort study. BMJ 2005;331:1050.

84. Ghambarian MH, Feenstra TL, Zwanikken P, Kalinina AM. Can prevention be improved? Proposal for an integrated intervention strategy. Prev Med 2004;39:337-343.

85. Nichter M. Introducing tobacco cessation in developing countries: an overview of Quit Tobacco International. Tob Control 2006;15:12-17.

86. Ackermann-Liebrich U, Leuenberger P, Schwartz J, Schindler C, Monn C, Bolognini G, Bongard JP, Brändli O, Domenighetti G. Elsasser S, et al. Lung function and long term exposure to air pollutants in Switzerland. Study on Air Pollution and Lung Diseases in Adults (SAPALDIA) team. Am J Respir Crit Care Med 1997;155:122-129.

87. Reis AL. Response to bronchodilators. In: Clausen J, editor. Pulmonary function testing: guidelines and controversies. New York: Academic Press; 1982.

88. Janelli LM, Scherer YK, Schmieder LE. Can a pulmonary health teaching program alter patients' ability to cope with COPD? Rehabil Nurs 1991:16:199-202.

89. Ashikaga T, Vacek PM, Lewis SO. Evaluation of a community-based education program for individuals with chronic obstructive pulmonary disease. J Rehabil 1980;46:23-27.

90. Toshima MT, Kaplan RM, Ries AL. Experimental evaluation of rehabilitation in chronic obstructive pulmonary disease: short-term effects on exercise endurance and health status. Health Psychol 1990;9:237-252.

91. Celli BR. Pulmonary rehabilitation in patients with COPD. Am $J$ Respir Crit Care Med 1995;152:861-864.

92. Stewart MA. Effective physician-patient communication and health outcomes: a review. CMAJ 1995;152:1423-1433.

93. Clark NM, Nothwehr F, Gong M, Evans D, Maiman LA, Hurwitz ME, Roloff D, Mellins RD. Physician-patient partnership in managing chronic illness. Acad Med 1995;70:957-959.

94. Heffner JE, Fahy B, Hilling L, Barbieri C. Outcomes of advance directive education of pulmonary rehabilitation patients. Am J Respir Crit Care Med 1997;155:1055-1059.

95. Pauwels RA, Lofdahl CG, Laitinen LA, Schouten JP, Postma DS, Pride NB, Ohlsson SV. Long-term treatment with inhaled budesonide in persons with mild chronic obstructive pulmonary disease who continue smoking. European Respiratory Society Study on Chronic Obstructive Pulmonary Disease. N Engl J Med 1999;340:19481953.

96. Vestbo J, Sorensen T, Lange P, Brix A, Torre P, Viskum K. Long-term effect of inhaled budesonide in mild and moderate chronic obstructive pulmonary disease: a randomised controlled trial. Lancet 1999; 353:1819-1823.

97. Burge PS, Calverley PM, Jones PW, Spencer S, Anderson JA, Maslen TK. Randomised, double blind, placebo controlled study of flutica- sone propionate in patients with moderate to severe chronic obstructive pulmonary disease: the ISOLDE trial. BMJ 2000;320:1297-1303.

98. Vathenen AS, Britton JR, Ebden P, Cookson JB, Wharrad HJ, Tattersfield AE. High-dose inhaled albuterol in severe chronic airflow limitation. Am Rev Respir Dis 1988;138:850-855.

99. Gross NJ, Petty TL, Friedman M, Skorodin MS, Silvers GW, Donohue JF. Dose response to ipratropium as a nebulized solution in patients with chronic obstructive pulmonary disease: a three-center study. $A m$ Rev Respir Dis 1989;139:1188-1191.

100. Chrystyn H, Mulley BA, Peake MD. Dose response relation to oral theophylline in severe chronic obstructive airways disease. BMJ 1988;297:1506-1510.

101. Higgins BG, Powell RM, Cooper S, Tattersfield AE. Effect of salbutamol and ipratropium bromide on airway calibre and bronchial reactivity in asthma and chronic bronchitis. Eur Respir J 1991;4:415-420.

102. Ikeda A, Nishimura K, Koyama H, Izumi T. Bronchodilating effects of combined therapy with clinical dosages of ipratropium bromide and salbutamol for stable COPD: comparison with ipratropium bromide alone. Chest 1995;107:401-405.

103. Guyatt GH, Townsend M, Pugsley SO, Keller JL, Short HD, Taylor DW, Newhouse MT. Bronchodilators in chronic air-flow limitation: effects on airway function, exercise capacity, and quality of life. Am Rev Respir Dis 1987;135:1069-1074.

104. Man WD, Mustfa N, Nikoletou D, Kaul S, Hart N, Rafferty GF, Donaldson N, Polkey MI, Moxham J. Effect of salmeterol on respiratory muscle activity during exercise in poorly reversible COPD. Thorax 2004;59:471-476.

105. O’Donnell DE, Fluge T, Gerken F, Hamilton A, Webb K, Aguilaniu B, Make B, Magnussen H. Effects of tiotropium on lung hyperinflation, dyspnoea and exercise tolerance in COPD. Eur Respir J 2004;23:832840.

106. Vincken W, van Noord JA, Greefhorst AP, Bantje TA, Kesten S, Korducki L, Cornelissen PJ. Improved health outcomes in patients with COPD during 1 yr's treatment with tiotropium. Eur Respir J 2002;19:209-216.

107. Mahler DA, Donohue JF, Barbee RA, Goldman MD, Gross NJ, Wisniewski ME, Yancey SW, Zakes BA, Rickard KA, Anderson WH. Efficacy of salmeterol xinafoate in the treatment of COPD. Chest 1999;115:957-965.

108. Dahl R, Greefhorst LA, Nowak D, Nonikov V, Byrne AM, Thomson MH, Till D, Della Cioppa G. Inhaled formoterol dry powder versus ipratropium bromide in chronic obstructive pulmonary disease. Am J Respir Crit Care Med 2001;164:778-784.

109. Oostenbrink JB, Rutten-van Molken MP, Al MJ, Van Noord JA, Vincken W. One-year cost-effectiveness of tiotropium versus ipratropium to treat chronic obstructive pulmonary disease. Eur Respir J 2004:23:241-249.

110. Niewoehner DE, Rice K, Cote C, Paulson D, Cooper JA Jr, Korducki L, Cassino C, Kesten S. Prevention of exacerbations of chronic obstructive pulmonary disease with tiotropium, a once-daily inhaled anticholinergic bronchodilator: a randomized trial. Ann Intern Med 2005;143:317-326.

111. Casaburi R, Kukafka D, Cooper CB, Witek TJ Jr, Kesten S. Improvement in exercise tolerance with the combination of tiotropium and pulmonary rehabilitation in patients with COPD. Chest 2005;127:809817.

112. COMBIVENT Inhalation Aerosol Study Group. In chronic obstructive pulmonary disease, a combination of ipratropium and albuterol is more effective than either agent alone: an 85-day multicenter trial. Chest 1994;105:1411-1419.

113. COMBIVENT Inhalation Solution Study Group. Routine nebulized ipratropium and albuterol together are better than either alone in COPD. Chest 1997;112:1514-1521.

114. Gross N, Tashkin D, Miller R, Oren J, Coleman W, Linberg S. Inhalation by nebulization of albuterol-ipratropium combination (Dey combination) is superior to either agent alone in the treatment of chronic obstructive pulmonary disease. Dey Combination Solution Study Group. Respiration (Herrlisheim) 1998;65:354-362.

115. Taylor DR, Buick B, Kinney C, Lowry RC, McDevitt DG. The efficacy of orally administered theophylline, inhaled salbutamol, and a combination of the two as chronic therapy in the management of chronic bronchitis with reversible air-flow obstruction. Am Rev Respir Dis 1985;131:747-751

116. van Noord JA, de Munck DR, Bantje TA, Hop WC, Akveld ML, Bommer AM. Long-term treatment of chronic obstructive pulmonary 
disease with salmeterol and the additive effect of ipratropium. Eur Respir J 2000;15:878-885.

117. ZuWallack RL, Mahler DA, Reilly D, Church N, Emmett A, Rickard K, Knobil K. Salmeterol plus theophylline combination therapy in the treatment of COPD. Chest 2001;119:1661-1670.

118. Bellia V, Foresi A, Bianco S, Grassi V, Olivieri D, Bensi G, Volonte M. Efficacy and safety of oxitropium bromide, theophylline and their combination in COPD patients: a double-blind, randomized, multicentre study (BREATH trial). Respir Med 2002;96:881-889.

119. Guyatt GH, Berman LB, Townsend M, Pugsley SO, Chambers LW. A measure of quality of life for clinical trials in chronic lung disease. Thorax 1987;42:773-778.

120. O'Driscoll BR, Kay EA, Taylor RJ, Weatherby H, Chetty MC, Bernstein A. A long-term prospective assessment of home nebulizer treatment. Respir Med 1992;86:317-325.

121. Jenkins SC, Heaton RW, Fulton TJ, Moxham J. Comparison of domiciliary nebulized salbutamol and salbutamol from a metered-dose inhaler in stable chronic airflow limitation. Chest 1987;91:804-807.

122. The Lung Health Study Research Group. Effect of inhaled triamcinolone on the decline in pulmonary function in chronic obstructive pulmonary disease: Lung Health Study II. N Engl J Med 2000; 343:1902-1909.

123. Mahler DA, Wire P, Horstman D, Chang CN, Yates J, Fischer T, Shah T. Effectiveness of fluticasone propionate and salmeterol combination delivered via the Diskus device in the treatment of chronic obstructive pulmonary disease. Am J Respir Crit Care Med 2002;166: 1084-1091.

124. Jones PW, Willits LR, Burge PS, Calverley PM. Disease severity and the effect of fluticasone propionate on chronic obstructive pulmonary disease exacerbations. Eur Respir J 2003;21:68-73.

125. Calverley P, Pauwels R, Vestbo J, Jones P, Pride N, Gulsvik A, Anderson J, Maden C. Combined salmeterol and fluticasone in the treatment of chronic obstructive pulmonary disease: a randomised controlled trial. Lancet 2003;361:449-456.

126. Szafranski W, Cukier A, Ramirez A, Menga G, Sansores R, Nahabedian S, Peterson S, Olsson H. Efficacy and safety of budesonide/formoterol in the management of chronic obstructive pulmonary disease. Eur Respir J 2003;21:74-81.

127. Spencer S, Calverley PM, Burge PS, Jones PW. Impact of preventing exacerbations on deterioration of health status in COPD. Eur Respir J 2004;23:698-702.

128. van der Valk P, Monninkhof E, van der Palen J, Zielhuis G, van Herwaarden C. Effect of discontinuation of inhaled corticosteroids in patients with chronic obstructive pulmonary disease: the COPE study. Am J Respir Crit Care Med 2002;166:1358-1363.

129. Sin DD, Wu L, Anderson JA, Anthonisen NR, Buist AS, Burge PS, Calverley PM, Connett JE, Lindmark B, Pauwels RA, et al. Inhaled corticosteroids and mortality in chronic obstructive pulmonary disease. Thorax 2005;60:992-997.

130. Hanania NA, Darken P, Horstman D, Reisner C, Lee B, Davis S, Shah $\mathrm{T}$. The efficacy and safety of fluticasone propionate $(250 \mathrm{microg}) /$ salmeterol (50 microg) combined in the Diskus inhaler for the treatment of COPD. Chest 2003;124:834-843.

131. Calverley PM, Boonsawat W, Cseke Z, Zhong N, Peterson S, Olsson H. Maintenance therapy with budesonide and formoterol in chronic obstructive pulmonary disease. Eur Respir J 2003;22:912-919.

132. Decramer M, de Bock V, Dom R. Functional and histologic picture of steroid-induced myopathy in chronic obstructive pulmonary disease. Am J Respir Crit Care Med 1996;153:1958-1964.

133. Decramer M, Lacquet LM, Fagard R, Rogiers P. Corticosteroids contribute to muscle weakness in chronic airflow obstruction. Am J Respir Crit Care Med 1994;150:11-16.

134. Decramer M, Stas KJ. Corticosteroid-induced myopathy involving respiratory muscles in patients with chronic obstructive pulmonary disease or asthma. Am Rev Respir Dis 1992;146:800-802.

135. Wongsurakiat P, Maranetra KN, Wasi C, Kositanont U, Dejsomritrutai $\mathrm{W}$, Charoenratanakul S. Acute respiratory illness in patients with COPD and the effectiveness of influenza vaccination: a randomized controlled study. Chest 2004;125:2011-2020.

136. Nichol KL, Margolis KL, Wuorenma J, Von Sternberg T. The efficacy and cost effectiveness of vaccination against influenza among elderly persons living in the community. $N$ Engl J Med 1994;331:778-784.

137. Wongsurakiat P, Lertakyamanee J, Maranetra KN, Jongriratanakul S, Sangkaew S. Economic evaluation of influenza vaccination in Thai chronic obstructive pulmonary disease patients. $J$ Med Assoc Thai 2003;86:497-508.
138. Edwards KM, Dupont WD, Westrich MK, Plummer WD Jr, Palmer PS, Wright PF. A randomized controlled trial of cold-adapted and inactivated vaccines for the prevention of influenza A disease. J Infect Dis 1994;169:68-76.

139. Hak E, van Essen GA, Buskens E, Stalman W, de Melker RA. Is immunising all patients with chronic lung disease in the community against influenza cost effective? Evidence from a general practice based clinical prospective cohort study in Utrecht, The Netherlands. J Epidemiol Community Health 1998;52:120-125.

140. Woodhead M, Blasi F, Ewig S, Huchon G, Ieven M, Ortqvist A. Schaberg T, Torres A, van der Heijden G, Verheij TJ. Guidelines for the management of adult lower respiratory tract infections. Eur Respir J 2005;26:1138-1180.

141. Jackson LA, Neuzil KM, Yu O, Benson P, Barlow WE, Adams AL, Hanson CA, Mahoney LD, Shay DK, Thompson WW. Effectiveness of pneumococcal polysaccharide vaccine in older adults. $N$ Engl $J$ Med 2003;348:1747-1755.

142. Advisory Committee on Immunization Practices. Prevention of pneumococcal disease: recommendations of the Advisory Committee on Immunization Practices (ACIP) [Internet]. MMWR Morb Mortal Wkly Rep 1997;46(RR-08):1-24. Available from: http://www.cdc.gov/ $\mathrm{mmwr} / \mathrm{preview} / \mathrm{mmwrhtml} / 00047135 . \mathrm{htm}$.

143. Alfageme I, Vazaque R, Reyes N, Munoz J, Fernandez A, Hernandez M, Merino M, Perez J, Lima J. Clinical efficiacy of anti-pneumococcal vaccination in patients with COPD. Thorax 2006;61:189-195.

144. Francis RS, May JR, Spicer CC. Chemotherapy of bronchitis: influence of penicillin and tetracycline administered daily, or intermittently for exacerbations. BMJ 1961;2:979-985.

145. Francis RS, Spicer CC. Chemotherapy in chronic bronchitis: influence of daily penicillin and teracycline on exacerbations and their cost: a report to the research committee of the British Tuberculosis Association by their Chronic Bronchitis subcommittee. BMJ 1960;1:297-303.

146. Medical Research Council. Value of chemoprophylaxis and chemotherapy in early chronic bronchitis: a report to the Medical Research Council by their Working Party on trials of chemotherapy in early chronic bronchitis. BMJ 1966;1(5499):1317-1322.

147. Johnston RN, McNeill RS, Smith DH, Dempster MB, Nairn JR, Purvis MS, Watson JM, Ward FG. Five-year winter chemoprophylaxis for chronic bronchitis. BMJ 1969;4:265-269.

148. Isada CM, Stoller JK. Chronic bronchitis: the role of antibiotics. In: Niederman MS, Sarosi GA, Glassroth J, editors. Respiratory infections: a scientific basis for management. London: W.B. Saunders; 1994. pp. 621-633.

149. Siafakas NM, Bouros D. Management of acute exacerbation of chronic obstructive pulmonary disease. In: Postma DS, Siafakas NM, editors. Management of chronic obstructive pulmonary disease. Sheffield, UK: ERS Monograph; 1998. pp. 264-277.

150. Allegra L, Cordaro CI, Grassi C. Prevention of acute exacerbations of chronic obstructive bronchitis with carbocysteine lysine salt monohydrate: a multicenter, double-blind, placebo-controlled trial. Respiration (Herrlisheim) 1996;63:174-180.

151. Guyatt GH, Townsend M, Kazim F, Newhouse MT. A controlled trial of ambroxol in chronic bronchitis. Chest 1987;92:618-620.

152. Petty TL. The National Mucolytic Study: results of a randomized, double-blind, placebo-controlled study of iodinated glycerol in chronic obstructive bronchitis. Chest 1990;97:75-83.

153. Siafakas NM, Vermeire P, Pride NB, Paoletti P, Gibson J, Howard P, Yernault JC, Decramer M, Higenbottam T, Postma DS, et al. Optimal assessment and management of chronic obstructive pulmonary disease (COPD). The European Respiratory Society Task Force. Eur Respir J 1995;8:1398-1420.

154. American Thoracic Society. Standards for the diagnosis and care of patients with chronic obstructive pulmonary disease (COPD) and asthma. Am Rev Respir Dis 1987;136:225-244.

155. Hansen NC, Skriver A, Brorsen-Riis L, Balslov S, Evald T, Maltbaek $\mathrm{N}$, Gunnersen G, Garsdal $\mathrm{P}$, Sander $\mathrm{P}$, Pedersen JZ, et al. Orally administered $\mathrm{N}$-acetylcysteine may improve general wellbeing in patients with mild chronic bronchitis. Respir Med 1994;88: 531-535.

156. British Thoracic Society Research Committee. Oral N-acetylcysteine and exacerbation rates in patients with chronic bronchitis and severe airways obstruction. Thorax 1985;40:832-835.

157. Boman G, Backer U, Larsson S, Melander B, Wahlander L. Oral acetylcysteine reduces exacerbation rate in chronic bronchitis: report of a trial organized by the Swedish Society for Pulmonary Diseases. Eur J Respir Dis 1983;64:405-415. 
158. Rasmussen JB, Glennow C. Reduction in days of illness after long-term treatment with $\mathrm{N}$ - acetylcysteine controlled-release tablets in patients with chronic bronchitis. Eur Respir J 1988;1:351-355.

159. Decramer M, Rutten-van Molken M, Dekhuijzen PN, Troosters T, van Herwaarden C, Pellegrino R, van Schayck CP, Olivieri D, Del Donno $\mathrm{M}$, De Backer W, et al. Effects of $\mathrm{N}$-acetylcysteine on outcomes in chronic obstructive pulmonary disease (Bronchitis Randomized on NAC Cost-Utility Study, BRONCUS): a randomised placebocontrolled trial. Lancet 2005;365:1552-1560.

160. Collet JP, Shapiro P, Ernst P, Renzi T, Ducruet T, Robinson A. Effects of an immunostimulating agent on acute exacerbations and hospitalizations in patients with chronic obstructive pulmonary disease. The PARI-IS Study Steering Committee and Research Group (Prevention of Acute Respiratory Infection by an Immunostimulant). Am J Respir Crit Care Med 1997;156:1719-1724.

161. Li J, Zheng JP, Yuan JP, Zeng GQ, Zhong NS, Lin CY. Protective effect of a bacterial extract against acute exacerbation in patients with chronic bronchitis accompanied by chronic obstructive pulmonary disease. Chin Med J (Engl) 2004;117:828-834.

162. Anthonisen NR. OM-8BV for COPD. Am J Respir Crit Care Med 1997;156:1713-1714.

163. Irwin RS, Boulet LP, Cloutier MM, Fuller R, Gold PM, Hoffstein V, Ing AJ, McCool FD, O'Byrne $\mathrm{P}$, Poe RH, et al. Managing cough as a defense mechanism and as a symptom: a consensus panel report of the American College of Chest Physicians. Chest 1998;114(2 Suppl Managing):133S-181S

164. Barbera JA, Roger N, Roca J, Rovira I, Higenbottam TW, RodriguezRoisin R. Worsening of pulmonary gas exchange with nitric oxide inhalation in chronic obstructive pulmonary disease. Lancet 1996; 347:436-440.

165. Jones AT, Evans TW. NO: COPD and beyond. Thorax 1997;52:S16-S21.

166. Jennings AL, Davies AN, Higgins JP, Gibbs JS, Broadley KE. A systematic review of the use of opioids in the management of dyspnoea. Thorax 2002;57:939-944.

167. Eiser N, Denman WT, West C, Luce P. Oral diamorphine: lack of effect on dyspnoea and exercise tolerance in the "pink puffer" syndrome. Eur Respir J 1991;4:926-931.

168. Young IH, Daviskas E, Keena VA. Effect of low dose nebulised morphine on exercise endurance in patients with chronic lung disease. Thorax 1989;44:387-390.

169. Woodcock AA, Gross ER, Gellert A, Shah S, Johnson M, Geddes DM. Effects of dihydrocodeine, alcohol, and caffeine on breathlessness and exercise tolerance in patients with chronic obstructive lung disease and normal blood gases. N Engl J Med 1981;305:1611-1616.

170. Rice KL, Kronenberg RS, Hedemark LL, Niewoehner DE. Effects of chronic administration of codeine and promethazine on breathlessness and exercise tolerance in patients with chronic airflow obstruction. Br J Dis Chest 1987;81:287-292.

171. Poole PJ, Veale AG, Black PN. The effect of sustained-release morphine on breathlessness and quality of life in severe chronic obstructive pulmonary disease. Am J Respir Crit Care Med 1998;157:1877-1880.

172. Nici L, Donner C, Wouters E, Zuwallack R; ATS/ERS Pulmonary Rehabilitation Writing Committee. American Thoracic Society/ European Respiratory Society statement on pulmonary rehabilitation. Am J Respir Crit Care Med 2006;173:1390-1413.

173. Foglio K, Bianchi L, Bruletti G, Battista L, Pagani M, Ambrosino N. Long-term effectiveness of pulmonary rehabilitation in patients with chronic airway obstruction. Eur Respir J 1999;13:125-132.

174. Young P, Dewse M, Fergusson W, Kolbe J. Improvements in outcomes for chronic obstructive pulmonary disease (COPD) attributable to a hospital-based respiratory rehabilitation programme. Aust $N Z \mathrm{~J}$ Med 1999;29:59-65.

175. Griffiths TL, Burr ML, Campbell IA, Lewis-Jenkins V, Mullins J, Shiels K, Turner-Lawlor PJ, Payne N, Newcombe RG, Ionescu AA, et al. Results at 1 year of outpatient multidisciplinary pulmonary rehabilitation: a randomised controlled trial. Lancet 2000;355:362-368. [Published erratum appears in Lancet 2000;355:1280].

176. Goldstein RS, Gort EH, Stubbing D, Avendano MA, Guyatt GH. Randomised controlled trial of respiratory rehabilitation. Lancet 1994:344:1394-1397.

177. Wijkstra PJ, Van Altena R, Kraan J, Otten V, Postma DS, Koeter GH. Quality of life in patients with chronic obstructive pulmonary disease improves after rehabilitation at home. Eur Respir J 1994;7:269-273.

178. McGavin CR, Gupta SP, Lloyd EL, McHardy GJ. Physical rehabilitation for the chronic bronchitic: results of a controlled trial of exercises in the home. Thorax 1977;32:307-311.
179. Nocturnal Oxygen Therapy Trial Group. Continuous or nocturnal oxygen therapy in hypoxemic chronic obstructive lung disease: a clinical trial. Ann Intern Med 1980;93:391-398.

180. Report of the Medical Research Council Working Party. Long term domiciliary oxygen therapy in chronic hypoxic cor pulmonale complicating chronic bronchitis and emphysema. Lancet 1981;1:681-686.

181. Tarpy SP, Celli BR. Long-term oxygen therapy. N Engl J Med 1995; 333:710-714.

182. Clinical indications for noninvasive positive pressure ventilation in chronic respiratory failure due to restrictive lung disease, COPD, and nocturnal hypoventilation consensus conference report. Chest 1999;116: 521-534.

183. Mehran RJ, Deslauriers J. Indications for surgery and patient work-up for bullectomy. Chest Surg Clin N Am 1995;5:717-734.

184. Naunheim KS. Wood DE, Mohsenifar Z, Sternberg AL, Criner GJ, DeCamp MM, Deschamps CC, Martinez FJ, Sciurba FC, Tonascia J, et al. Long-term follow-up of patients receiving lung-volume-reduction surgery versus medical therapy for severe emphysema by the National Emphysema Treatment Trial Research Group. Ann Thorac Surg 2006;82:431-443.

185. Trulock EP. Lung transplantation. Am J Respir Crit Care Med 1997;155:789-818.

186. Theodore J, Lewiston N. Lung transplantation comes of age. N Engl J Med 1990;322:772-774.

187. Hosenpud JD, Bennett LE, Keck BM, Fiol B, Boucek MM, Novick RJ. The Registry of the International Society for Heart and Lung Transplantation: fifteenth official report-1998. J Heart Lung Transplant 1998; 17:656-668.

188. Annual report of the U.S. Scientific Registry for Transplant Recipients and the Organ Procurement and Transplantation Network. Transplant data: 1988-1994. Washington, DC: Division of Transplantation, Health Resources and Services Administraion, U.S. Department of Health and Human Services; 1995.

189. Hosenpud JD, Bennett LE, Keck BM, Edwards EB, Novick RJ. Effect of diagnosis on survival benefit of lung transplantation for end-stage lung disease. Lancet 1998;351:24-27.

190. Maurer JR, Frost AE, Estenne M, Higenbottam T, Glanville AR. International guidelines for the selection of lung transplant candidates. The International Society for Heart and Lung Transplantation, the American Thoracic Society, the American Society of Transplant Physicians, the European Respiratory Society. Transplantation 1998;66:951-956.

191. Smetana GW. Preoperative pulmonary evaluation. $N$ Engl J Med 1999;340:937-944.

192. Trayner E Jr, Celli BR. Postoperative pulmonary complications. Med Clin North Am 2001;85:1129-1139.

193. Weisman IM. Cardiopulmonary exercise testing in the preoperative assessment for lung resection surgery. Semin Thorac Cardiovasc Surg 2001;13:116-125.

194. Bolliger CT, Perruchoud AP. Functional evaluation of the lung resection candidate. Eur Respir J 1998;11:198-212.

195. Schuurmans MM, Diacon AH, Bolliger CT. Functional evaluation before lung resection. Clin Chest Med 2002;23:159-172.

196. Celli BR, MacNee W. Standards for the diagnosis and treatment of patients with COPD: a summary of the ATS/ERS position paper. Eur Respir J 2004;23:932-946.

197. Regueiro CR, Hamel MB, Davis RB, Desbiens N, Connors AF Jr, Phillips RS. A comparison of generalist and pulmonologist care for patients hospitalized with severe chronic obstructive pulmonary disease: resource intensity, hospital costs, and survival. SUPPORT Investigators (Study to Understand Prognoses and Preferences for Outcomes and Risks of Treatment). Am J Med 1998;105:366-372.

198. Gibson PG, Wlodarczyk JH, Wilson AJ, Sprogis A. Severe exacerbation of chronic obstructive airways disease: health resource use in general practice and hospital. J Qual Clin Pract 1998;18:125-133.

199. Anthonisen NR, Manfreda J, Warren CP, Hershfield ES, Harding GK, Nelson NA. Antibiotic therapy in exacerbations of chronic obstructive pulmonary disease. Ann Intern Med 1987;106:196-204.

200. Warren PM, Flenley DC, Millar JS, Avery A. Respiratory failure revisited: acute exacerbations of chronic bronchitis between 1961-68 and 1970-76. Lancet 1980;1:467-470.

201. Gunen H, Hacievliyagil SS, Kosar F, Mutlu LC, Gulbas G, Pehlivan E, Sahin I, Kizkin O. Factors affecting survival of hospitalised patients with COPD. Eur Respir J 2005;26:234-241.

202. Rodriguez-Roisin R. Toward a consensus definition for COPD exacerbations. Chest 2000;117(5, Suppl 2):398S-401S. 
203. Burge S, Wedzicha JA. COPD exacerbations: definitions and classifications. Eur Respir J Suppl 2003;41:46s-53s.

204. Seemungal TA, Donaldson GC, Bhowmik A, Jeffries DJ, Wedzicha JA. Time course and recovery of exacerbations in patients with chronic obstructive pulmonary disease. Am J Respir Crit Care Med 2000;161:1608-1613.

205. White AJ, Gompertz S, Stockley RA. Chronic obstructive pulmonary disease. 6: The aetiology of exacerbations of chronic obstructive pulmonary disease. Thorax 2003;58:73-80.

206. Monso E, Ruiz J, Rosell A, Manterola J, Fiz J, Morera J, Ausina V. Bacterial infection in chronic obstructive pulmonary disease: a study of stable and exacerbated outpatients using the protected specimen brush. Am J Respir Crit Care Med 1995;152:1316-1320.

207. Pela R, Marchesani F, Agostinelli C, Staccioli D, Cecarini L, Bassotti $\mathrm{C}$, Sanguinetti CM. Airways microbial flora in COPD patients in stable clinical conditions and during exacerbations: a bronchoscopic investigation. Monaldi Arch Chest Dis 1998;53:262-267.

208. Sethi S, Evans N, Grant BJ, Murphy TF. New strains of bacteria and exacerbations of chronic obstructive pulmonary disease. $N$ Engl $J$ Med 2002;347:465-471.

209. Sethi S, Wrona C, Grant BJ, Murphy TF. Strain-specific immune response to Haemophilus influenzae in chronic obstructive pulmonary disease. Am J Respir Crit Care Med 2004;169:448-453.

210. Sethi S, Muscarella K, Evans N, Klingman KL, Grant BJ, Murphy TF. Airway inflammation and etiology of acute exacerbations of chronic bronchitis. Chest 2000;118:1557-1565.

211. White AJ, Gompertz S, Bayley DL, Hill SL, O'Brien C, Unsal I, Stockley RA. Resolution of bronchial inflammation is related to bacterial eradication following treatment of exacerbations of chronic bronchitis. Thorax 2003;58:680-685.

212. Murphy TF, Brauer AL, Grant BJ, Sethi S. Moraxella catarrhalis in chronic obstructive pulmonary disease: burden of disease and immune response. Am J Respir Crit Care Med 2005;172:195-199.

213. Emerman CL, Connors AF, Lukens TW, Effron D, May ME. Relationship between arterial blood gases and spirometry in acute exacerbations of chronic obstructive pulmonary disease. Ann Emerg Med 1989;18:523-527.

214. Adams SJM, Luther M. Antibiotics are associated with lower relapse rates in outpatients with acute exacerbations of chronic obstructive pulmonary disease. Chest 2000;117:1345-1352.

215. Mueller C, Laule-Kiliam K, Frana B, Rodriguez D, Rudez J, Swcholer A, Buser P, Pfisterer M, Perruchoud AP. The use of B-natriuretic peptide in the managment of elderly patients with acute dyspnea. J Intern Med 2005;258:77-85.

216. Richards AM, Nicholls MG, Epiner EA, Lainchbury JD, Troughton RW, Elliott J, Framton C, Turner J, Crozier IG, Yandle TG. B-type natriuretic peptide and ejectrion fraction for prognosis after myocardial infarction. Circulation 2003;107:2786.

217. Davies L, Wilkinson M, Bonner S, Calverley PM, Angus RM. "Hospital at home" versus hospital care in patients with exacerbations of chronic obstructive pulmonary disease: prospective randomised controlled trial. BMJ 2000;321:1265-1268.

218. Ojoo JC, Moon T, McGlone S, Martin K, Gardiner ED, Greenstone MA, Morice AH. Patients' and carers' preferences in two models of care for acute exacerbations of COPD: results of a randomised controlled trial. Thorax 2002;57:167-169.

219. Skwarska E, Cohen G, Skwarski KM, Lamb C, Bushell D, Parker S, MacNee W. Randomized controlled trial of supported discharge in patients with exacerbations of chronic obstructive pulmonary disease. Thorax 2000;55:907-912.

220. Hernandez C, Casas A, Escarrabill J, Alonso J, Puig-Junoy J, Farrero E, Vilagut G, Collvinent B, Rodriguez-Roisin R, Roca J, et al. Home hospitalisation of exacerbated chronic obstructive pulmonary disease patients. Eur Respir J 2003;21:58-67.

221. Thompson WH, Nielson CP, Carvalho P, Charan NB, Crowley JJ. Controlled trial of oral prednisone in outpatients with acute COPD exacerbation. Am J Respir Crit Care Med 1996;154:407-412.

222. Davies L, Angus RM, Calverley PM. Oral corticosteroids in patients admitted to hospital with exacerbations of chronic obstructive pulmonary disease: a prospective randomised controlled trial. Lancet 1999;354:456-460.

223. Niewoehner DE, Erbland ML, Deupree RH, Collins D, Gross NJ, Light RW, Anderson P, Morgan NA. Effect of systemic glucocorticoids on exacerbations of chronic obstructive pulmonary disease. Department of Veterans Affairs Cooperative Study Group. N Engl J Med 1999;340:1941-1947.
224. Maltais F, Ostinelli J, Bourbeau J, Tonnel AB, Jacquemet N, Haddon J, Rouleau M, Boukhana M, Martinot JB, Duroux P. Comparison of nebulized budesonide and oral prednisolone with placebo in the treatment of acute exacerbations of chronic obstructive pulmonary disease: a randomized controlled trial. Am J Respir Crit Care Med 2002;165:698-703.

225. Aaron SD, Vandemheen KL, Hebert P, Dales R, Stiell IG, Ahuja J, Dickinson G, Brison R, Rowe BH, Dreyer J, et al. Outpatient oral prednisone after emergency treatment of chronic obstructive pulmonary disease. $N$ Engl J Med 2003;348:2618-2625.

226. Rodriguez-Roisin R. COPD exacerbations. 5: Management. Thorax 2006; 61:535-544.

227. Connors AF, Jr., Dawson NV, Thomas C, Harrell FE, Jr., Desbiens N, Fulkerson WJ, Kussin P, Bellamy P, Goldman L, Knaus WA. Outcomes following acute exacerbation of severe chronic obstructive lung disease. The SUPPORT investigators (Study to Understand Prognoses and Preferences for Outcomes and Risks of Treatments). Am J Respir Crit Care Med 1996;154:959-967.

228. Shepperd S, Harwood D, Gray A, Vessey M, Morgan P. Randomised controlled trial comparing hospital at home care with inpatient hospital care. II: Cost minimisation analysis. BMJ 1998;316:17911796.

229. Gravil JH, Al-Rawas OA, Cotton MM, Flanigan U, Irwin A, Stevenson RD. Home treatment of exacerbations of chronic obstructive pulmonary disease by an acute respiratory assessment service. Lancet 1998;351:1853-1855.

230. Soderstrom L, Tousignant $P$, Kaufman $T$. The health and cost effects of substituting home care for inpatient acute care: a review of the evidence. CMAJ 1999;160:1151-1155.

231. National Institute for Clinical Excellence (NICE). Chronic obstructive pulmonary disease: national clinical guideline on management of chronic obstructive pulmonary disease in adults in primary and secondary care. Thorax 2004;59:1-232.

232. Barbera JA, Reyes A, Roca J, Montserrat JM, Wagner PD, RodriguezRoisin R. Effect of intravenously administered aminophylline on ventilation/perfusion inequality during recovery from exacerbations of chronic obstructive pulmonary disease. Am Rev Respir Dis 1992; 145:1328-1333.

233. Mahon JL, Laupacis A, Hodder RV, McKim DA, Paterson NA, Wood TE, Donner A. Theophylline for irreversible chronic airflow limitation: a randomized study comparing $\mathrm{n}$ of 1 trials to standard practice. Chest 1999;115:38-48.

234. Lloberes P, Ramis L, Montserrat JM, Serra J, Campistol J, Picado C, Agusti-Vidal A. Effect of three different bronchodilators during an exacerbation of chronic obstructive pulmonary disease. Eur Respir $J$ 1988;1:536-539.

235. Murciano D, Aubier M, Lecocguic Y, Pariente R. Effects of theophylline on diaphragmatic strength and fatigue in patients with chronic obstructive pulmonary disease. $N$ Engl J Med 1984;311:349-353.

236. Emerman CL, Connors AF, Lukens TW, May ME, Effron D. Theophylline concentrations in patients with acute exacerbation of COPD. Am J Emerg Med 1990;8:289-292.

237. Barr RG, Rowe BH, Camargo CA Jr. Methylxanthines for exacerbations of chronic obstructive pulmonary disease: meta-analysis of randomised trials. BMJ 2003;327:643.

238. Duffy N, Walker P, Diamantea F, Calverley PM, Davies L. Intravenous aminophylline in patients admitted to hospital with non-acidotic exacerbations of chronic obstructive pulmonary disease: a prospective randomised controlled trial. Thorax 2005;60:713-717.

239. Seemungal T, Harper-Owen R, Bhowmik A, Moric I, Sanderson G, Message S, Maccallum P, Meade TW, Jeffries DJ, Johnston SL, et al. Respiratory viruses, symptoms, and inflammatory markers in acute exacerbations and stable chronic obstructive pulmonary disease. Am J Respir Crit Care Med 2001;164:1618-1623.

240. Blasi F, Damato S, Cosentini R, Tarsia P, Raccanelli R, Centanni S, Allegra L. Chlamydia pneumoniae and chronic bronchitis: association with severity and bacterial clearance following treatment. Thorax 2002;57:672-676.

241. Seemungal TA, Wedzicha JA, MacCallum PK, Johnston SL, Lambert PA. Chlamydia pneumoniae and COPD exacerbation. Thorax 2002;57:1087-1088. [Author reply, 8-9.]

242. Greenstone M, Lasserson TJ. Doxapram for ventilatory failure due to exacerbations of chronic obstructive pulmonary disease. Cochrane Database Syst Rev 2003;1:CD000223.

243. Lightowler JV, Wedzicha JA, Elliott MW, Ram FS. Non-invasive positive pressure ventilation to treat respiratory failure resulting from 
exacerbations of chronic obstructive pulmonary disease: Cochrane systematic review and meta-analysis. BMJ 2003;326:185.

244. Meyer TJ, Hill NS. Noninvasive positive pressure ventilation to treat respiratory failure. Ann Intern Med 1994;120:760-770.

245. Brochard L, Mancebo J, Wysocki M, Lofaso F, Conti G, Rauss A, Simonneau G, Benito S, Gasparetto A, Lemaire F. Noninvasive ventilation for acute exacerbations of chronic obstructive pulmonary disease. N Engl J Med 1995;333:817-822.

246. Kramer N, Meyer TJ, Meharg J, Cece RD, Hill NS. Randomized, prospective trial of noninvasive positive pressure ventilation in acute respiratory failure. Am J Respir Crit Care Med 1995;151:1799_ 1806.

247. Bott J, Carroll MP, Conway JH, Keilty SE, Ward EM, Brown AM, Paul EA, Elliott MW, Godfrey RC, Wedzicha JA, et al. Randomised controlled trial of nasal ventilation in acute ventilatory failure due to chronic obstructive airways disease. Lancet 1993;341:1555-1557.

248. Plant PK, Owen JL, Elliott MW. Early use of non-invasive ventilation for acute exacerbations of chronic obstructive pulmonary disease on general respiratory wards: a multicentre randomised controlled trial. Lancet 2000;355:1931-1935.

249. Esteban A, Anzueto A, Alia I, Gordo F, Apezteguia C, Palizas F, Cide $\mathrm{D}$, Goldwaser R, Soto L, Bugedo G, et al. How is mechanical ventilation employed in the intensive care unit? An international utilization review. Am J Respir Crit Care Med 2000;161:1450-1458.

250. International Consensus Conferences in Intensive Care Medicine. Noninvasive positive pressure ventilation in acute respiratory failure. Am J Respir Crit Care Med 2001;163:283-291.

251. Plant PK, Owen JL, Elliott MW. Non-invasive ventilation in acute exacerbations of chronic obstructive pulmonary disease: long term survival and predictors of in-hospital outcome. Thorax 2001;56:708712.

252. Conti G, Antonelli M, Navalesi P, Rocco M, Bufi M, Spadetta G, Meduri GU. Noninvasive vs. conventional mechanical ventilation in patients with chronic obstructive pulmonary disease after failure of medical treatment in the ward: a randomized trial. Intensive Care Med 2002;28:1701-1707.

253. Esteban A, Anzueto A, Frutos F, Alia I, Brochard L, Stewart TE, Benito S, Epstein SK, Apezteguia C, Nightingale P, et al. Characteristics and outcomes in adult patients receiving mechanical ventilation: a 28-day international study. JAMA 2002;287:345-355.

254. Esteban A, Frutos F, Tobin MJ, Alia I, Solsona JF, Valverdu I, Fernandez R, de la Cal MA, Benito S, Tomas R, et al. A comparison of four methods of weaning patients from mechanical ventilation. Spanish Lung Failure Collaborative Group. $N$ Engl J Med 1995;332: 345-350.
255. Brochard L, Rauss A, Benito S, Conti G, Mancebo J, Rekik N, Gasparetto A, Lemaire F. Comparison of three methods of gradual withdrawal from ventilatory support during weaning from mechanical ventilation. Am J Respir Crit Care Med 1994;150:896-903.

256. Hilbert G, Gruson D, Portel L, Gbikpi-Benissan G, Cardinaud JP. Noninvasive pressure support ventilation in COPD patients with postextubation hypercapnic respiratory insufficiency. Eur Respir $J$ 1998;11:1349-1353.

257. Kessler R, Faller M, Fourgaut G, Mennecier B, Weitzenblum E. Predictive factors of hospitalization for acute exacerbation in a series of 64 patients with chronic obstructive pulmonary disease. Am J Respir Crit Care Med 1999;159:158-164.

258. Mushlin AI, Black ER, Connolly CA, Buonaccorso KM, Eberly SW. The necessary length of hospital stay for chronic pulmonary disease. JAMA 1991;266:80-83.

259. Cotton MM, Bucknall CE, Dagg KD, Johnson MK, MacGregor G, Stewart C, Stevenson RD. Early discharge for patients with exacerbations of chronic obstructive pulmonary disease: a randomized controlled trial. Thorax 2000;55:902-906.

260. Hughes SL, Weaver FM, Giobbie-Hurder A, Manheim L, Henderson W, Kubal JD, Ulasevich A, Cummings J. Effectiveness of teammanaged home-based primary care: a randomized multicenter trial. JAMA 2000;284:2877-2885.

261. Hermiz O, Comino E, Marks G, Daffurn K, Wilson S, Harris M. Randomised controlled trial of home based care of patients with chronic obstructive pulmonary disease. BMJ 2002;325:938.

262. Stoller JK, Lange PA. Inpatient management of chronic obstructive pulmonary disease. Respir Care Clin N Am 1998;4:425-438.

263. Peach H, Pathy MS. Follow-up study of disability among elderly patients discharged from hospital with exacerbations of chronic bronchitis. Thorax 1981;36:585-589.

264. Eaton T, Withy S, Garrett JE, Mercer J, Whitlock RM, Rea HH. Spirometry in primary care practice: the importance of quality assurance and the impact of spirometry workshops. Chest 1999;116:416-423.

265. Schermer TR, Jacobs JE, Chavannes NH, Hartman J, Folgering HT, Bottema BJ, van Weel C. Validity of spirometric testing in a general practice population of patients with chronic obstructive pulmonary disease (COPD). Thorax 2003;58:861-866.

266. Schermer T, Eaton T, Pauwels R, van Weel C. Spirometry in primary care: is it good enough to face demands like World COPD Day? Eur Respir J 2003;22:725-727.

267. Rea H, McAuley S, Stewart A, Lamont C, Roseman P, Didsbury P. A chronic disease management programme can reduce days in hospital for patients with chronic obstructive pulmonary disease. Intern Med J 2004;34:608-614. 